\title{
The influence of warm-season precipitation on the diel cycle of the surface energy balance and carbon dioxide at a Colorado subalpine forest site
}

\author{
S. P. Burns ${ }^{1,2}$, P. D. Blanken ${ }^{1}$, A. A. Turnipseed ${ }^{3}$, J. Hu${ }^{4}$, and R. K. Monson ${ }^{5}$ \\ ${ }^{1}$ Department of Geography, University of Colorado, Boulder, Colorado, USA \\ ${ }^{2}$ National Center for Atmospheric Research, Boulder, Colorado, USA \\ ${ }^{3}$ 2B Technologies, Inc., Boulder, Colorado, USA \\ ${ }^{4}$ Department of Ecology, Montana State University, Bozeman, Montana, USA \\ ${ }^{5}$ School of Natural Resources and the Environment, University of Arizona, Tucson, Arizona, USA
}

Correspondence to: S. P. Burns (sean@ucar.edu)

Received: 15 May 2015 - Published in Biogeosciences Discuss.: 16 June 2015

Revised: 25 November 2015 - Accepted: 26 November 2015 - Published: 15 December 2015

\begin{abstract}
Precipitation changes the physical and biological characteristics of an ecosystem. Using a precipitation-based conditional sampling technique and a 14 year data set from a $25 \mathrm{~m}$ micrometeorological tower in a high-elevation subalpine forest, we examined how warm-season precipitation affected the above-canopy diel cycle of wind and turbulence, net radiation $R_{\text {net }}$, ecosystem eddy covariance fluxes (sensible heat $H$, latent heat $\mathrm{LE}$, and $\mathrm{CO}_{2}$ net ecosystem exchange NEE) and vertical profiles of scalars (air temperature $T_{\mathrm{a}}$, specific humidity $q$, and $\mathrm{CO}_{2}$ dry mole fraction $\chi_{\mathrm{c}}$ ). This analysis allowed us to examine how precipitation modified these variables from hourly (i.e., the diel cycle) to multi-day timescales (i.e., typical of a weather-system frontal passage).

During mid-day we found the following: (i) even though precipitation caused mean changes on the order of 50-70\% to $R_{\text {net }}, H$, and LE, the surface energy balance (SEB) was relatively insensitive to precipitation with mid-day closure values ranging between 90 and $110 \%$, and (ii) compared to a typical dry day, a day following a rainy day was characterized by increased ecosystem uptake of $\mathrm{CO}_{2}(\mathrm{NEE}$ increased by $\approx 10 \%$ ), enhanced evaporative cooling (mid-day LE increased by $\approx 30 \mathrm{~W} \mathrm{~m}^{-2}$ ), and a smaller amount of sensible heat transfer (mid-day $H$ decreased by $\approx 70 \mathrm{~W} \mathrm{~m}^{-2}$ ). Based on the mean diel cycle, the evaporative contribution to total evapotranspiration was, on average, around $6 \%$ in dry conditions and between 15 and $25 \%$ in partially wet conditions. Furthermore, increased LE lasted at least $18 \mathrm{~h}$ following a
\end{abstract}

rain event. At night, even though precipitation (and accompanying clouds) reduced the magnitude of $R_{\text {net }}$, LE increased from $\approx 10$ to over $20 \mathrm{~W} \mathrm{~m}^{-2}$ due to increased evaporation. Any effect of precipitation on the nocturnal SEB closure and NEE was overshadowed by atmospheric phenomena such as horizontal advection and decoupling that create measurement difficulties. Above-canopy mean $\chi_{c}$ during wet conditions was found to be about $2-3 \mu \mathrm{mol} \mathrm{mol}{ }^{-1}$ larger than $\chi_{\mathrm{c}}$ on dry days. This difference was fairly constant over the full diel cycle suggesting that it was due to synoptic weather patterns (different air masses and/or effects of barometric pressure). Finally, the effect of clouds on the timing and magnitude of daytime ecosystem fluxes is described.

\section{Introduction}

Warm-season precipitation is a common perturbation that changes the physical and biological properties of a forest ecosystem. The most obvious effect is the wetting of vegetation and ground surfaces which provides liquid water for evaporation and changes the surface energy partitioning between sensible heat flux $H$ and latent heat flux LE (i.e., evapotranspiration). Such changes are important in the modeling of ecosystem process on both local and global scales (e.g., Bonan, 2008; Moene and Van Dam, 2014). After entering the soil, rain can have either of two opposing mechanophysical 
effects on the soil-atmosphere $\mathrm{CO}_{2}$ exchange. It can either displace high $\mathrm{CO}_{2}$-laden air from the soil, or suppress the release of $\mathrm{CO}_{2}$ because of inhibited diffusion/transport due to water-filled soil pore space (Hirano et al., 2003; Huxman et al., 2004; Ryan and Law, 2005). The soil and the atmosphere near the ground are closely coupled, and therefore soil moisture changes also affect near-ground atmospheric properties (Betts and Ball, 1995; Pattantyús-Ábrahám and Jánosi, 2004).

Rain has been shown to cause short-lived increases in soil respiration by microorganisms (by as much as a factor of ten) in a diverse range of forest and grassland-type ecosystems (e.g., Irvine and Law, 2002; Lee et al., 2004; Huxman et al., 2004; Austin et al., 2004; Xu et al., 2004; Tang et al., 2005; Ivans et al., 2006; Misson et al., 2006; Jarvis et al., 2007; Jenerette et al., 2008; Inglima et al., 2009; Savage et al., 2009; Munson et al., 2010; Bowling et al., 2011; Parton et al., 2012). The pulse of $\mathrm{CO}_{2}$ emitted from soil that accompanies precipitation following a long drought period is one aspect of the so-called Birch effect (named after H.F. Birch (1912-1982), see Jarvis et al. (2007); Unger et al. (2010) for a summary). The timing, size, and duration of the precipitation event (as well as the number of previous wet-dry cycles) all affect the magnitude of the microbial and plant/tree responses to the water entering the system. The response of soil respiration to a rain pulse typically has an exponential decay with time (Xu et al., 2004; Jenerette et al., 2008). The Birch effect is especially important for the carbon balance in arid or water-limited ecosystems where background soil respiration rates are generally low.

Net ecosystem exchange of $\mathrm{CO}_{2}$ (NEE) is calculated from the above-canopy eddy covariance $\mathrm{CO}_{2}$ vertical flux plus the temporal changes in the $\mathrm{CO}_{2}$ dry mole fraction between the flux measurement-level and the ground (i.e., the $\mathrm{CO}_{2}$ storage term). The studies listed in the previous paragraph have used a combination of eddy-covariance, soil chambers, and continuous in situ $\mathrm{CO}_{2}$ mixing ratio measurements to examine ecosystem responses to precipitation. Many of these studies have also shown that $\mathrm{CO}_{2}$ pulses due to the Birch effect have an important influence on the seasonal and annual budget of NEE for that particular ecosystem (e.g., Lee et al., 2004; Jarvis et al., 2007; Parton et al., 2012). In the current study we will not be concerned with mechanistic or biological aspects of the Birch effect, but instead focus on how precipitation affects above-canopy NEE and any possible implications on the annual carbon budget.

Evaporation from wet surfaces was initially modeled by Penman (1948) using available energy (primarily net radiation), the difference between saturation vapor pressure and atmospheric vapor pressure at a given temperature (i.e., $e_{\mathrm{S}}-e_{\mathrm{d}}$, also known as the vapor pressure deficit, VPD), and aerodynamic resistances to formulate an expression for surface LE. The concepts by Penman were extended to include transpiration by Monteith (1965) who introduced the concept of canopy resistance (a resistance to transpiration which is in series with the aerodynamic resistance, but controlled by the leaf stomates) leading to the Penman-Monteith equation for latent heat flux over dry vegetation. Based on these formulations, the fundamental variables which are believed to control evapotranspiration are net radiation, sensible heat flux, atmospheric stability (which affects the aerodynamic resistances), stomatal resistance, and VPD. In a fully wet canopy, transpiration becomes small and most available energy is used to evaporate liquid water intercepted by the canopy elements and within the soil (e.g., Grelle et al., 1997; Geiger et al., 2003). It has been questioned whether stomates respond to the rate of transpiration rather than VPD (e.g., Monteith, 1995; Pieruschka et al., 2010). It has also been shown that stability/wind speed only has a small direct effect on transpiration (e.g., Kim et al., 2014). In our study, we will not consider any effects on transpiration due to seasonal changes in leaf area (e.g., Lindroth, 1985) or variation in soil water potential (e.g., Tan and Black, 1976).

Close to vegetated surfaces, it is known that the atmospheric fluxes of $\mathrm{CO}_{2}$ and water vapor are correlated to each other because the leaf stomates control both photosynthesis and transpiration (Monteith, 1965; Brutsaert, 1982; Jarvis and McNaughton, 1986; McNaughton and Jarvis, 1991; Katul et al., 2012; Wang and Dickinson, 2012; Beerling, 2015). There are also temporal changes (and feedbacks) to LE related to boundary layer growth and entrainment which are summarized by van Heerwaarden et al. $(2009,2010)$. One of the drawbacks to the eddy covariance measurement of LE is that the contributions from the physical process of evaporation are not easily separated from the biological process of transpiration without making some assumptions of stomatal behavior (e.g., Scanlon and Kustas, 2010), using isotopic methods (e.g., Yakir and Sternberg, 2000; Williams et al., 2004; Werner et al., 2012; Jasechko et al., 2013; Berkelhammer et al., 2013), or having additional measurements, such as sap flow (e.g., Hogg et al., 1997; Oishi et al., 2008; Staudt et al., 2011) or weighing lysimeters (e.g., Grimmond et al., 1992; Rana and Katerji, 2000; Blanken et al., 2001). Another technique uses above-canopy eddy-covariance instruments for evapotranspiration coupled with sub-canopy instruments to estimate evaporation (e.g., Blanken et al., 1997; Law et al., 2000; Wilson et al., 2001; Staudt et al., 2011); this method, however, can have issues with varying flux footprint sizes (Misson et al., 2007). An accurate way to separate transpiration and evaporation has been a goal of the ecosystem-measurement community for many years, especially an understanding of how this ratio changes during the transition between a wet and dry canopy (e.g., Shuttleworth, 1976, 2007).

Numerous studies have looked at the annual and interannual relationship between precipitation, water fluxes and NEE at the climate scale (Aubinet et al., 2000; Wilson et al., 2001; Law et al., 2002; Malhi et al., 2002; Thomas et al., 2009; Hu et al., 2010a; Polley et al., 2010, and many others). However, a comprehensive examination of the effect of pre- 
cipitation on ecosystem-scale eddy covariance fluxes at the diel (i.e., hourly or "weather-front") time scale is lacking.

Our study uses 14 years of data from a high-elevation subalpine forest AmeriFlux site to explore how warm-season rain events (defined as a daily precipitation total greater than $3 \mathrm{~mm}$ ) change the mean meteorological variables (horizontal wind speed $U$, air temperature $T_{\mathrm{a}}$ and specific humidity $q$ ), the surface energy fluxes (latent and sensible heat), and carbon dioxide (both $\mathrm{CO}_{2}$ mole fraction and NEE) over the diel cycle. From this analysis we can evaluate both the magnitude and timing of how the energy balance terms and NEE are modified by the presence of rainwater in the soil and on the vegetation. Precipitation is also closely linked to changes in air temperature and humidity as weather fronts and storm systems pass by the site. Since NEE and the energy fluxes depend on meteorological variables such as net radiation, air temperature and VPD, it can be difficult to separate out the effect of precipitation vs. other environmental changes (Turnipseed et al., 2009; Riveros-Iregui et al., 2011).

Though the primary goal of our study is to quantify how precipitation modifies the warm-season mean diel cycle of the measured scalars and fluxes, a secondary goal is to present the 14 year mean and interannual variability of the energy fluxes and NEE measured at the Niwot Ridge Subalpine Forest AmeriFlux site. These results will serve as an update to the original set of papers (e.g., Monson et al., 2002; Turnipseed et al., 2002) that examined the ecosystem fluxes from the Niwot Ridge AmeriFlux site over 12 years ago and were based on 2 years of measurements.

\section{Data and methods}

\subsection{Site description}

Our study uses data from the Niwot Ridge Subalpine Forest AmeriFlux site (site US-NR1, more information available at http://ameriflux.lbl.gov) located in the Rocky Mountains about $8 \mathrm{~km}$ east of the Continental Divide. The US-NR1 measurements started in November 1998. The site is on the side of an ancient moraine with granitic-rocky-podzolic soil (typically classified as a loamy sand in dry locations) overlain by a shallow layer $(\approx 10 \mathrm{~cm})$ of organic material (Marr, 1961; Scott-Denton et al., 2003). The tree density near the US-NR1 $27 \mathrm{~m}$ walk-up scaffolding tower is around 4000 trees ha $^{-1}$ with a leaf area index (LAI) of $3.8-4.2 \mathrm{~m}^{2} \mathrm{~m}^{-2}$ and tree heights of 12-13 m (Turnipseed et al., 2002; Monson et al., 2010). The subalpine forest surrounding the US-NR1 tower was established in the early 1900s following logging operations, and is primarily composed of subalpine fir (Abies lasiocarpa var. bifolia) and Englemann spruce (Picea engelmannii) west of the tower, and lodgepole pine (Pinus contorta) east of the tower. Smaller patches of aspen (Populus tremuloides) and limber pine (Pinus flexilis) are also present. Empirical evidence from wind-thrown trees suggest rooting depths of 40-100 cm which is consistent with depths from similar subalpine forests (e.g., Alexander, 1987) and as discussed in $\mathrm{Hu}$ et al. (2010a). Recent analysis of tree ring cores at the site has revealed a significant presence of remnant trees which are older (over 200 years old) and larger than the trees that became established after logging in the early 1900s (R. Alexander, F. Babst, and D. J. P. Moore, University of Arizona, unpublished data).

At the US-NR1 subalpine forest, ecosystem processes are closely linked to the presence of snow (Knowles et al., 2014), which typically arrives in October or November, reaches a maximum depth in early April (snow water equivalent $(\mathrm{SWE}) \approx 30 \mathrm{~cm})$, and melts by early June. Sometime in March or April, the snowpack becomes isothermal (Burns et al., 2013) and liquid water becomes available in the soil, which initiates the photosynthetic uptake of $\mathrm{CO}_{2}$ by the forest (Monson et al., 2005). The long-term mean annual precipitation at the site is around $800 \mathrm{~mm}$ with about $40 \%$ of the total from warm-season rain, which typically occurs every 2-4 days and has an average daily total of around $4 \mathrm{~mm}$ (Hu et al., 2010a). According to the Köppen-Geiger climate classification system (Kottek et al., 2006) the site is type Dfc, which corresponds to a cold, snowy/moist continental climate with precipitation spread fairly evenly throughout the year. The forest could also be classified as climate type $\mathrm{H}$ which is sometimes used for mountain locations (Greenland, 2005). The summer precipitation timing is primarily controlled by the mountain-plain atmospheric dynamics and thus usually occurs in the afternoon when upslope flows trigger convective thunderstorms (Brazel and Brazel, 1983; Parrish et al., 1990; Whiteman, 2000; Turnipseed et al., 2004; Burns et al., 2011; Zardi and Whiteman, 2013).

\subsection{Surface energy balance, measurements, and data details}

The terms in the surface energy balance (SEB) are

$R_{\mathrm{a}} \equiv R_{\mathrm{net}}-G-S_{\mathrm{tot}}=H+\mathrm{LE}+E_{\mathrm{adv}}$,

where $R_{\mathrm{a}}$ is the available energy, $R_{\text {net }}$ is net radiation, $G$ is soil heat flux at the ground surface, and $S_{\text {tot }}$ is the heat and water vapor storage terms in the biomass and airspace between the ground and flux measurement level as well as the energy consumed by photosynthesis. All terms in Eq. (1) have units of $\mathrm{W} \mathrm{m}^{-2}$. Positive $R_{\text {net }}$ indicates radiative warming of the surface, whereas a positive sign for the other terms in Eq. (1) indicate surface cooling or energy being stored. The $S_{\text {tot }}$ terms are typically on the order of $10 \%$ of $R_{\text {net }}$ (Turnipseed et al., 2002; Oncley et al., 2007; Lindroth et al., 2010). $S_{\text {tot }}$ and $G$ are discussed in detail in Appendix A2. The horizontal advection of heat and water vapor $\left(E_{\mathrm{adv}}\right)$ requires spatially distributed measurements, and is thought to be a primary reason that Eq. (1) does not balance at most flux sites (Leuning et al., 2012). When the winds are light (below about $3-4 \mathrm{~ms}^{-1}$ ), horizontal advection becomes im- 
portant which results in a lack of SEB closure at the US-NR1 site (Turnipseed et al., 2002). In our discussions, the SEB closure fraction refers to the ratio of the sum of the turbulent fluxes to the available energy, i.e., $(H+\mathrm{LE}) / R_{\mathrm{a}}$.

$R_{\text {net }}$ was measured at $25 \mathrm{~m}$ above ground level (a.g.l.) with both a net (REBS, model Q-7.1) and four-component (Kipp and Zonen, model CNR1) radiometer. $R_{\text {net }}$ from the Q-7.1 sensor is about $15 \%$ closer to closing the SEB than with the CNR1 sensor (Turnipseed et al., 2002; Burns et al., 2012). Since the Q-7.1 radiometer operated during the entire 14 year period, it is the primary $R_{\text {net }}$ sensor in our study. Calculation of the top-of-the-atmosphere incoming solar radiation $\left(Q_{\mathrm{SW}}^{\downarrow}\right)_{\mathrm{TOA}}$ is described in Appendix A1. The turbulent fluxes $H$ and LE were measured at $21.5 \mathrm{ma.g} .1$. using standard eddy covariance flux data-processing techniques (e.g., Aubinet et al., 2012) and instrumentation (a 3-D sonic anemometer (Campbell Scientific, model CSAT3), krypton hygrometer (Campbell Scientific, model KH2O), and closedpath infrared gas analyzer; IRGA, LI-COR, model LI-6262). Further details on the specific instrumentation and dataprocessing techniques are provided elsewhere (Monson et al., 2002; Turnipseed et al., 2002, 2003; Burns et al., 2013). Additional measurements used in our study are described in Appendix A1 while further details about updates to the US-NR1 flux calculations are in Appendix A3.

\subsection{Analysis methods}

Precipitation is notoriously difficult to study because of its intermittent, binary nature (e.g., it will often start, stop, restart, and falls with varying intensity) which leads to nonnormal statistical properties (e.g., Zawadzki, 1973). To study the impact of rain, we followed a methodology similar to that of Turnipseed et al. (2009) and tagged days when the daily rainfall exceeded $3 \mathrm{~mm}$ as "wet" days. Table 1 shows the number of wet days for each year and warm-season month within our study. The choice to use $3 \mathrm{~mm}$ as the wet-day criteria was a balance between effectively capturing the effect of precipitation and providing enough wet periods to improve the wet-day statistics. If we designate the precipitation state of the preceding day with a lower-case letter, then diel patterns for "dry days following a dry day" (dDry days), "wet days following a dry day" (dWet days), "wet days following a wet day" (wWet days), and "dry days following a wet day" (wDry days) were analyzed to determine the effect of precipitation on the weather and climate as well as the fluxes. The term "wet days" includes both dWet and wWet days whereas the term "dry days" includes both dDry and wDry days. In addition to these categories, we further separated the dDry days into sunny (dDry-Clear) and cloudy (dDry-Cloudy) days. These techniques are similar to the clustering analysis used by Berkelhammer et al. (2013).

Since not every variable was continuously measured for all 14 years, some variables were necessarily analyzed over shorter periods than others. A summary of the variables stud- ied, the number of days each variable falls into each precipitation category, and gap-filling statistics of selected variables is provided in Table 2. Unless noted otherwise, the data analysis used in our study are based on 30 min statistics.

In addition to analyzing the mean diel cycle, we also examined the day-to-day variability in the diel cycle by calculating the standard deviation of the $30 \mathrm{~min}$ data within each composited time-of-day bin. This statistic will be designated the SD-Bin or variability. For brevity, the focus in the current paper is on the mean results; more details on variability can be found within the discussion paper (i.e., Burns et al., 2015). To further quantify and summarize the main results of our analysis, the diel cycle was broken up into three distinct periods: mid-day (10:00-14:00 MST), late evening (19:0023:00 MST), and nighttime (00:00-04:00 MST). Motivation for breaking up the night into two distinct periods is provided by Burns et al. (2011) who showed that the variability of the turbulence activity (expressed by the SD-Bin of the standard deviation of the vertical wind) increased by about a factor of two at around 23:00 MST (see their Fig. 4d). Other flux sites with sloped terrain have also shown distinct differences in the $\mathrm{CO}_{2}$ storage before and after midnight (e.g., Aubinet et al., 2005). Choosing these particular periods avoids the evening and morning transition periods which are complicated by the fluxes and scalar gradients becoming small and/or changing sign (e.g., Lothon et al., 2014).

In order to select the warm-season period, the smoothed seasonal cycle of NEE and the turbulent energy fluxes were calculated using a 20-day mean sliding window applied to the $30 \mathrm{~min}$ data. Smoothing removes the effect of large-scale weather patterns (and precipitation) which typically have a period of 4-7 days. Interannual variability was calculated by taking the standard deviation among the 14 yearly smoothed time series. Since our interest is in the diel cycle, these statistics were determined for mid-day (10:00-14:00 MST), nighttime (00:00-04:00 MST), and the full $(24 \mathrm{~h})$ time series.

The ecosystem respiration $R_{\text {eco }}$ was estimated for each 30 min time period based on measured nocturnal NEE (both with and without the friction velocity $\left(u_{*}\right)$ filter applied), as well as two flux-partitioning algorithms that separate NEE into $R_{\text {eco }}$ and gross primary productivity GPP (Stoy et al., 2006). One algorithm takes into account the seasonal temperature-dependence of $R_{\text {eco }}$ (Reichstein et al., 2005), and the other uses light-response curves (Lasslop et al., 2010). Reichstein and Lasslop $R_{\text {eco }}$ were calculated with online flux-partitioning software (Max Planck Institute, 2013). With regard to our analysis, $R_{\text {eco }}$ from the flux-partitioning methods and measured nocturnal NEE produced very similar results which are shown in Burns et al. (2015). Therefore, we only use the measured nocturnal NEE herein, and will not include the Reichstein or Lasslop $R_{\text {eco }}$ results. Unless noted otherwise, we will use the $u_{*}$ filtered NEE in our analysis. Further discussion of partitioning NEE at the US-NR1 site 
Table 1. Precipitation statistics for the US-NR1 AmeriFlux site. The number of days with a daily precipitation greater than 3 mm day ${ }^{-1}$ for each year and month is shown. These are defined as "wet" days in the analysis (see text for details). If the warm season started in June, then the May column is filled with "NA". The total cumulative precipitation from the wet days is given immediately below the number of days. In the two right-hand columns the cumulative precipitation from the wet days only and from all days within the warm season are provided. Precipitation units are $\mathrm{mm}$.

\begin{tabular}{|c|c|c|c|c|c|c|c|c|}
\hline \multirow[b]{2}{*}{ Year } & \multirow{2}{*}{$\begin{array}{c}\text { Day of } \\
\text { year } \\
\text { Start }^{\mathrm{a}}\end{array}$} & \multirow[b]{2}{*}{ May } & \multirow[b]{2}{*}{ June } & \multirow[b]{2}{*}{ July } & \multirow[b]{2}{*}{ August } & \multirow[b]{2}{*}{ September } & \multicolumn{2}{|c|}{ Cumulative precipitation } \\
\hline & & & & & & & (Wet days) & (Warm season) \\
\hline \multirow[t]{2}{*}{$2012^{b}$} & 135 & 3 & 2 & 12 & 2 & 5 & 24 & 140 \\
\hline & & 25.0 & 10.5 & 214.0 & 13.5 & 58.8 & 321.8 & 353.2 \\
\hline \multirow[t]{2}{*}{$2011^{b}$} & 168 & NA & 3 & 7 & 3 & 6 & 19 & 106 \\
\hline & & & 49.9 & 72.5 & 27.8 & 56.6 & 206.8 & 230.6 \\
\hline \multirow[t]{2}{*}{2010} & 156 & NA & 4 & 7 & 6 & 1 & 18 & 118 \\
\hline & & & 64.8 & 53.8 & 63.5 & 4.1 & 186.2 & 211.6 \\
\hline \multirow[t]{2}{*}{2009} & 153 & NA & 8 & 5 & 1 & 6 & 20 & 121 \\
\hline & & & 54.6 & 38.1 & 3.6 & 37.6 & 133.9 & 175.9 \\
\hline \multirow[t]{2}{*}{2008} & 160 & NA & 0 & 6 & 10 & 4 & 20 & 115 \\
\hline & & & & 31.7 & 134.9 & 49.9 & 216.5 & 241.9 \\
\hline \multirow[t]{2}{*}{2007} & 160 & NA & 1 & 8 & 8 & 6 & 23 & 114 \\
\hline & & & 10.7 & 74.9 & 57.9 & 32.8 & 176.3 & 211.5 \\
\hline \multirow{2}{*}{2006} & 142 & 1 & 1 & 6 & 2 & 5 & 15 & 132 \\
\hline & & 10.9 & 3.6 & 120.9 & 13.0 & 54.9 & 203.2 & 245.6 \\
\hline \multirow[t]{2}{*}{2005} & 152 & NA & 9 & 3 & 7 & 4 & 23 & 122 \\
\hline & & & 48.5 & 36.1 & 45.6 & 30.7 & 160.9 & 191.2 \\
\hline \multirow[t]{2}{*}{2004} & 138 & 1 & 11 & 6 & 7 & 6 & 31 & 137 \\
\hline & & 4.6 & 111.3 & 89.6 & 61.7 & 56.2 & 323.4 & 365.3 \\
\hline \multirow[t]{2}{*}{2003} & 153 & NA & 4 & 6 & 6 & 4 & 20 & 121 \\
\hline & & & 24.2 & 32.1 & 52.7 & 17.9 & 126.9 & 161.5 \\
\hline \multirow[t]{2}{*}{2002} & 137 & 2 & 3 & 5 & 6 & 6 & 22 & 137 \\
\hline & & 32.3 & 37.6 & 43.7 & 50.0 & 63.5 & 227.1 & 249.6 \\
\hline \multirow[t]{2}{*}{2001} & 142 & 2 & 4 & 7 & 7 & 4 & 24 & 132 \\
\hline & & 7.6 & 21.3 & 98.0 & 81.5 & 44.9 & 253.4 & 301.8 \\
\hline \multirow[t]{2}{*}{2000} & 142 & 2 & 6 & 4 & 6 & 6 & 24 & 133 \\
\hline & & 15.5 & 65.8 & 42.1 & 53.3 & 65.3 & 242.0 & 268.1 \\
\hline \multirow[t]{2}{*}{$1999^{c}$} & 158 & NA & 4 & 5 & 8 & 6 & 23 & 116 \\
\hline & & & 18.0 & 106.0 & 73.7 & 43.0 & 240.7 & 290.0 \\
\hline Total & & 11 & 60 & 87 & 79 & 69 & 306 & 1744 \\
\hline Mean & 149.7 & 6.8 & 37.2 & 75.3 & 52.3 & 44.0 & 215.6 & 249.8 \\
\hline
\end{tabular}


Table 2. Variables, symbols, units, and height above ground of measurements along with the number of days each variable falls within each precipitation category. Where appropriate, the percentage gap-filled $30 \mathrm{~min}$ data for each particular variable is shown. If any variable is missing for a $30 \mathrm{~min}$ period, then all variables within that particular group are excluded.

\begin{tabular}{|c|c|c|c|c|c|c|c|c|}
\hline \multirow[b]{2}{*}{ Variable } & \multirow[b]{2}{*}{ Symbol } & \multirow[b]{2}{*}{ Units } & \multirow{2}{*}{$\begin{array}{l}\text { Sensor } \\
\text { height } \\
(\mathrm{cm})\end{array}$} & \multicolumn{4}{|c|}{$\begin{array}{c}\text { Total number of days and } \\
\text { percentage of gap-filled values }\end{array}$} & \multirow[b]{2}{*}{ Note: } \\
\hline & & & & dDry & dWet & wWet & wDry & \\
\hline \multicolumn{3}{|c|}{ Measurements between 1999 and 2012} & & 1209 & 194 & 99 & 199 & \\
\hline Net radiation & $R_{\text {net }}$ & $\mathrm{W} \mathrm{m}^{-2}$ & 2550 & $0.5 \%$ & $2.1 \%$ & $2.8 \%$ & $1.6 \%$ & \\
\hline $\begin{array}{l}\text { Photosynthetically } \\
\text { active radiation }\end{array}$ & PAR & $\mu \mathrm{mol}$ photons $\mathrm{m}^{-2} \mathrm{~s}^{-1}$ & 2550 & $1.3 \%$ & $3.0 \%$ & $3.6 \%$ & $2.2 \%$ & \\
\hline \multicolumn{9}{|l|}{ Pressure } \\
\hline $\begin{array}{l}\text { Air temperature, } \\
\text { Relative humidity } \\
\text { Specific humidity }\end{array}$ & $\begin{array}{c}T_{\mathrm{a}}, \\
\mathrm{RH} \\
q\end{array}$ & $\begin{array}{c}{ }^{\circ} \mathrm{C}, \\
\text { percent } \\
\mathrm{g} \mathrm{kg}^{-1}\end{array}$ & 2150 & $0.6 \%$ & $2.3 \%$ & $2.9 \%$ & $1.5 \%$ & \\
\hline Soil temperature & $T_{\text {soil }}$ & ${ }^{\circ} \mathrm{C}$ & -5 & $3.5 \%$ & $3.5 \%$ & $4.3 \%$ & $4.7 \%$ & A \\
\hline $\begin{array}{l}\text { Wind speed, } \\
\text { Wind direction }\end{array}$ & $\begin{array}{c}U, \\
\text { WD }\end{array}$ & $\begin{array}{c}\mathrm{m} \mathrm{s}^{-1} \\
\text { deg from true } \mathrm{N}\end{array}$ & 2150 & $1.7 \%$ & $5.8 \%$ & $11.0 \%$ & $3.2 \%$ & $\mathrm{~B}$ \\
\hline Friction velocity & $u_{*}$ & $\mathrm{~m} \mathrm{~s}^{-1}$ & 2150 & $2.3 \%$ & $5.5 \%$ & $7.9 \%$ & $3.0 \%$ & \\
\hline Sensible heat flux & $H$ & $\mathrm{~W} \mathrm{~m}^{-2}$ & 2150 & $6.0 \%$ & $15.8 \%$ & $29.1 \%$ & $10.9 \%$ & $\mathrm{C}$ \\
\hline Latent heat flux & LE & $\mathrm{W} \mathrm{m}^{-2}$ & 2150 & $7.2 \%$ & $15.4 \%$ & $25.8 \%$ & $11.6 \%$ & $\mathrm{C}$ \\
\hline $\begin{array}{l}\text { Net ecosystem } \\
\text { exchange of } \mathrm{CO}_{2}\end{array}$ & NEE & $\mu \mathrm{molm}{ }^{-2} \mathrm{~s}^{-1}$ & 2150 & $12.0 \%$ & $24.9 \%$ & $37.5 \%$ & $20.8 \%$ & $\mathrm{C}$ \\
\hline \multicolumn{4}{|c|}{ Measurements between 2000 and 2012} & 1144 & 186 & 97 & 188 & \\
\hline Precipitation & Precip & $\mathrm{mm}(30 \mathrm{~min})^{-1}$ & 1050 & $3.8 \%$ & $2.8 \%$ & $3.0 \%$ & $1.5 \%$ & $\mathrm{D}$ \\
\hline \multicolumn{4}{|c|}{ Measurements between 2002 and 2012} & 924 & 148 & 76 & 148 & \multirow{3}{*}{ A } \\
\hline $\begin{array}{l}\text { Volumetric } \\
\text { water content }\end{array}$ & VWC & $\mathrm{m}^{3} \mathrm{~m}^{-3}$ & -5 & $0.01 \%$ & $0.01 \%$ & $0.01 \%$ & $0 \%$ & \\
\hline Soil heat flux & $G_{\text {plate }}$ & $\mathrm{W} \mathrm{m}^{-2}$ & -10 & $0.02 \%$ & $0.3 \%$ & $0.1 \%$ & $0.04 \%$ & \\
\hline \multicolumn{4}{|c|}{ Measurements between 2006 and 2012} & 530 & 83 & 46 & 82 & \multirow[b]{2}{*}{$\mathrm{E}$} \\
\hline $\begin{array}{l}\mathrm{CO}_{2} \text { Dry mole } \\
\text { fraction }\end{array}$ & $\chi_{\mathrm{c}}$ & $\mu \mathrm{molmol}^{-1}$ & 2150 & $\begin{array}{l}37.3 \% \\
10.7 \%\end{array}$ & $\begin{array}{c}34.8 \% \\
6.5 \%\end{array}$ & $\begin{array}{l}35.8 \% \\
6.2 \%\end{array}$ & $\begin{array}{l}37.3 \% \\
8.0 \%\end{array}$ & \\
\hline $\begin{array}{l}\text { Thermocouple } \\
\text { temperature }\end{array}$ & $T_{\mathrm{tc}}$ & ${ }^{\circ} \mathrm{C}$ & 2198 & $6.6 \%$ & $2.3 \%$ & $1.0 \%$ & $2.2 \%$ & \\
\hline
\end{tabular}

A: Details about the soil temperature and moisture measurements are in Appendix A1. B: When necessary, $U$ and WD were gap-filled with a prop-vane sensor at $25 \mathrm{~m}$ on US-NR1 tower. If the prop-vane data were unavailable, gap-filling was performed using $U$ and WD from the LTER C-1 climate station (as described in Appendix A1) which have been adjusted to US-NR1 winds using a linear relationship. C: NEE includes both the $u_{*}$ filter and storage term gap-filling. The flux data have been screened such that around $2 \%$ of the extreme values have been removed. D: Gap-filling statistics for the Met One tipping bucket on the US-NR1 tower are shown. The gap-filling flags for precipitation were incorrect prior to year 2003. Therefore, the gap-filling values listed here are for years 2003-2010. After year 2010, USCRN data were used (see Appendix A1 for details). E: Between years 2008 and 2010, the $\mathrm{CO}_{2}$ was sampled hourly rather than half-hourly. During periods with hourly measurements a linear interpolation was used to create data with half-hourly time stamps. The upper values shows the number of $30 \mathrm{~min}$ values missing prior to interpolation, while the lower numbers shows the number of missing values after interpolation. 
is provided elsewhere (Zobitz et al., 2008; Bowling et al., 2014).

Near the ground, the bulk Richardson number $\mathrm{Ri}_{\mathrm{b}}$ is often used to characterize stability. Large negative $\mathrm{Ri}_{\mathrm{b}}$ indicates unstable "free convection" conditions and large positive $\mathrm{Ri}_{\mathrm{b}}$ indicates strong stability. In more stable conditions, less mixing is expected and larger vertical scalar gradients should exist. We calculated $\mathrm{Ri}_{\mathrm{b}}$ between the highest $\left(z_{2}=21.5 \mathrm{~m}\right.$, around twice canopy height) and lowest $\left(z_{1}=2 \mathrm{~m}\right)$ measurement level using

$\mathrm{Ri}_{\mathrm{b}}=\frac{g}{\bar{T}_{\mathrm{a}}} \frac{\left(\theta_{2}-\theta_{1}\right)\left(z_{2}-z_{1}\right)}{U^{2}}$,

where $g$ is acceleration due to gravity, $\bar{T}_{\mathrm{a}}$ is the average air temperature of the layer, $\theta$ is potential temperature, and $U$ is the above-canopy horizontal vectorial mean wind speed (i.e., $U=\left(u^{2}+v^{2}\right)^{1 / 2}$ where $u$ and $v$ are the streamwise and crosswise planar-fit horizontal wind components). We did not use $U$ near the ground because this level is deep within the canopy where $U$ is small (less than $0.5 \mathrm{~m} \mathrm{~s}^{-1}$ ) due to the momentum absorbed by the needles, branches and boles of the trees. In this respect, the shear-generated turbulence is related to above-canopy wind speed whereas the buoyancy is related to the above-canopy/near-ground temperature difference.

\section{Results and discussion}

\subsection{Typical seasonal cycle and variability}

We chose to define the start of the warm season as the date when diurnal changes in the soil temperature first occurred (i.e., the date of near-complete snowpack ablation). For the 14 years of our study, the warm-season start dates ranged from mid-May to mid-June with an average start date of around 1 June (as shown in Fig. 1a and listed in Table 1). Though snow can occur during the warm season, it is a rare event and usually melts quickly. The start of the growing-season (based on NEE, as described in Hu et al., 2010a) typically preceded the start of the warm season by 2-4 weeks (Fig. 1a). The warm-season start date was also around the time that the volumetric soil moisture content (VWC) reached a maximum (Fig. 1b), and the month following the disappearance of the snowpack was usually when the soil dried out (though there were exceptions, such as 2004). In the warm season, large precipitation events led to a sharp increase in VWC followed by a gradual return (over several days or weeks) to drier soil conditions. We chose 30 September as the end of the warm season for reasons described below.

The typical smoothed seasonal cycles of above-canopy NEE, LE and $H$ are shown in Fig. 2a. For NEE, the dormant period (i.e., when the forest was inactive) was exemplified by almost no difference between the daytime and nighttime NEE, which lasted from roughly early November to mid-April. When daytime NEE switches from positive to negative, it indicates the start of the growing season. The snowmelt period exhibited strong $\mathrm{CO}_{2}$ uptake because soil respiration was suppressed due to low soil temperature (Fig. 2a). In February-March, daytime $H$ reached a maximum because net radiation increased and transpiration was small. Nighttime $H$ stayed at around $-50 \mathrm{Wm}^{-2}$ throughout the entire year. One might expect nocturnal $H$ in winter to be different than summer, but in winter most of the above-canopy $H$ was due to heat transfer between the forest canopy and atmosphere, not the atmosphere and snow-covered ground (Burns et al., 2013). Related to LE, there are two interesting observations in Fig. 2a. First, outside the growing season, daytime LE was larger than nighttime LE. This is presumably because air temperature is higher during the daytime which increases the saturation vapor pressure and results in a larger sublimation/evaporation rate (e.g., Dalton, 1802). Second, nighttime LE in winter was around $25 \mathrm{~W} \mathrm{~m}^{-2}$ which decreased to $10 \mathrm{~W} \mathrm{~m}^{-2}$ in summer. Despite warmer summer temperatures, we suspect the larger nocturnal LE in winter was due to the ubiquitous presence of a snowpack that serves as a source of sublimation/evaporation for $24 \mathrm{~h}$ every day (compared to summer when the ground periodically dries out). Also, winds are much stronger between November and February which promotes higher sublimation/evaporation. In the spring and summer LE increased during the day from around 50 to $150 \mathrm{~W} \mathrm{~m}^{-2}$ primarily due to increased forest transpiration as well as increased VPD. In July-August, as the soil dried out and warmed up, soil microbial activity increased (e.g., ScottDenton et al., 2006), and NEE moved closer to having photosynthetic uptake of $\mathrm{CO}_{2}$ balanced by respiration.

When winds are light and mechanical turbulence is small, decoupling between the air near the ground and abovecanopy air can occur (e.g., Baldocchi et al., 2000; Baldocchi, 2003). The nocturnal NEE data shown in Fig. 2a have been calculated both with (solid line) and without (dashed line) the $u_{*}$ filtering technique (Goulden et al., 1996) which replaces NEE during periods of weak ground-atmosphere coupling $\left(u_{*}<0.2 \mathrm{~m} \mathrm{~s}^{-1}\right)$ with an empirical relationship between NEE and soil temperature. Though the $u_{*}$ filter enhanced the value of nocturnal NEE by around $0.5 \mu \mathrm{mol} \mathrm{m}^{-2} \mathrm{~s}^{-1}$ compared to unfiltered NEE, the mid-summer increase was present in both. Recent research in the ecosystem-flux community has suggested that the standard deviation of the vertical wind $\sigma_{\mathrm{w}}$ (e.g., Acevedo et al., 2009; Oliveira et al., 2013; Alekseychik et al., 2013; Thomas et al., 2013) or the MoninObukhov stability parameter (e.g., Novick et al., 2004) are better measures of decoupling than $u_{*}$; however, the results we show are not going to be strongly affected by which variable is used to determine the coupling state.

The daytime interannual variability of NEE, LE and $H$ was larger than the nighttime interannual variability (Fig. 2b) due to the wide range of daytime surface solar conditions 

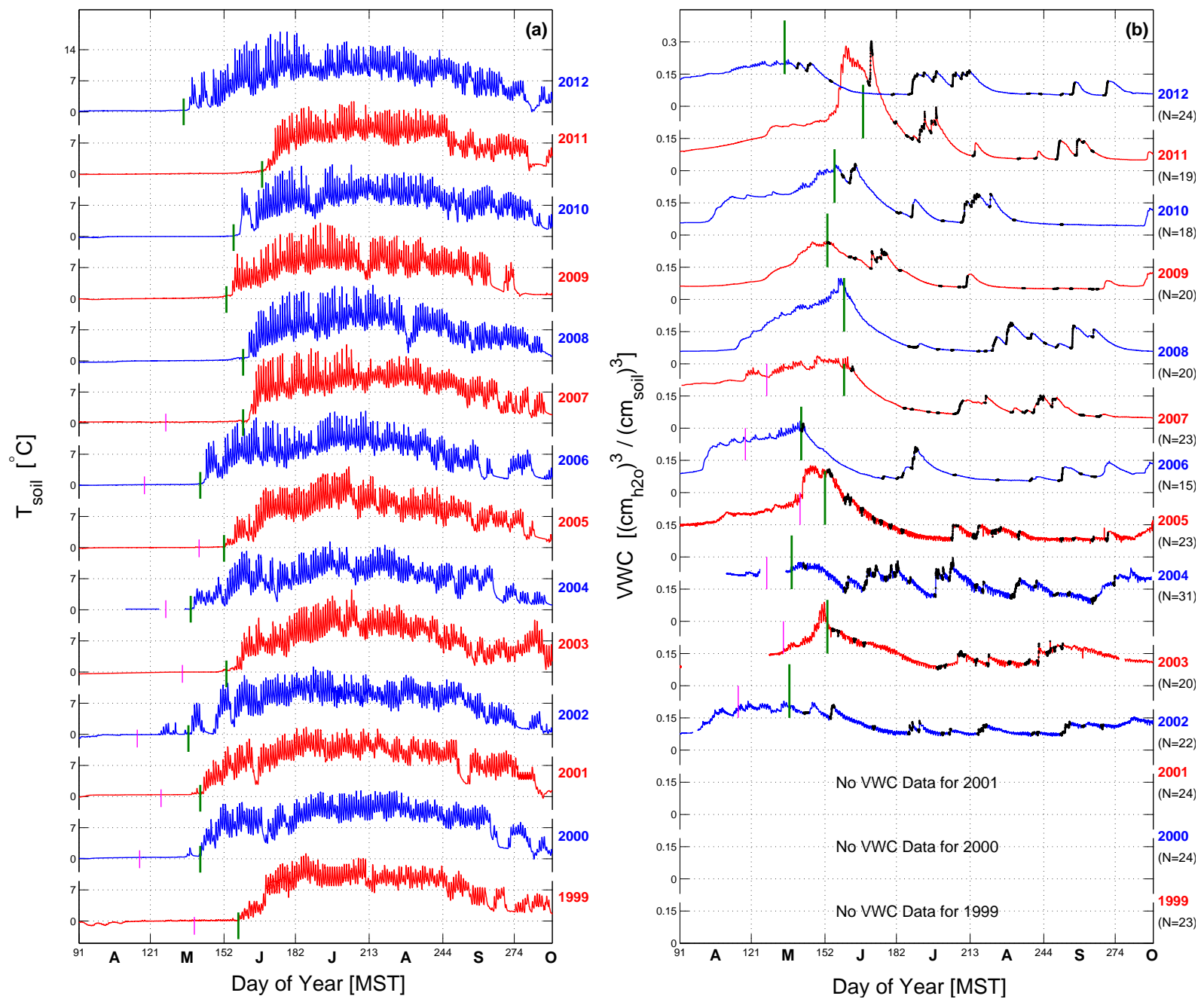

Figure 1. (a) Soil temperature and (b) soil moisture for years 1999 to 2012. In (b), the black dots indicate wet days and the number of wet days for each year is shown to the right of the panel underneath the year. The warm-season start date was chosen based on the date that the soil temperature diurnal changes started to occur as indicated by the vertical green lines. The vertical mauve lines for years 1999-2007 are the start date of the growing season as determined by Hu et al. (2010a). Starting with year 2006, a single set of soil sensors at a depth of $5 \mathrm{~cm}$ were used (see Appendix A1 for details).

(e.g., clear or cloudy days). The peak in the interannual variability of daytime NEE during April and May was due to year-to-year differences in the timing of snowmelt and initiation of photosynthetic forest uptake of $\mathrm{CO}_{2}$ at the site (Monson et al., 2005; Hu et al., 2010a). Though NEE interannual variability peaked at this time, there was no corresponding peak in LE or $H$ variability.

The average start of the warm season occurred when daytime NEE uptake was strong (greater than $8 \mu \mathrm{mol} \mathrm{m}^{-2} \mathrm{~s}^{-1}$ ) and immediately followed the peak in NEE interannual variability (Fig. 2b). There was not a similar increase in NEE variability to mark the end of the warm season; however, the date when daytime NEE decreased sharply was the end of September. For this reason, we chose the end of September as the end of the warm season. By choosing the end of
September we also avoid periods in October when snowfall occurred.

\subsection{The effect of wet conditions on the diel cycle}

After each day was organized into the precipitation categories described in Sect. 2.3, we observed a peak in precipitation during the early afternoon on wet days as would be expected for a mountain-plain type weather system (Fig. 3b). Over the 14 years of our study, the average length of time for a dry period was around 2.5 days with a standard deviation of 3 days. Two days in a row with above-average rain (i.e., wWet days) were recorded around 99 times out of 1744 total warm-season days between 1999 and 2012 (Table 2). These rare events were typically the result of large-scale synoptic weather systems which explains why significant morn- 

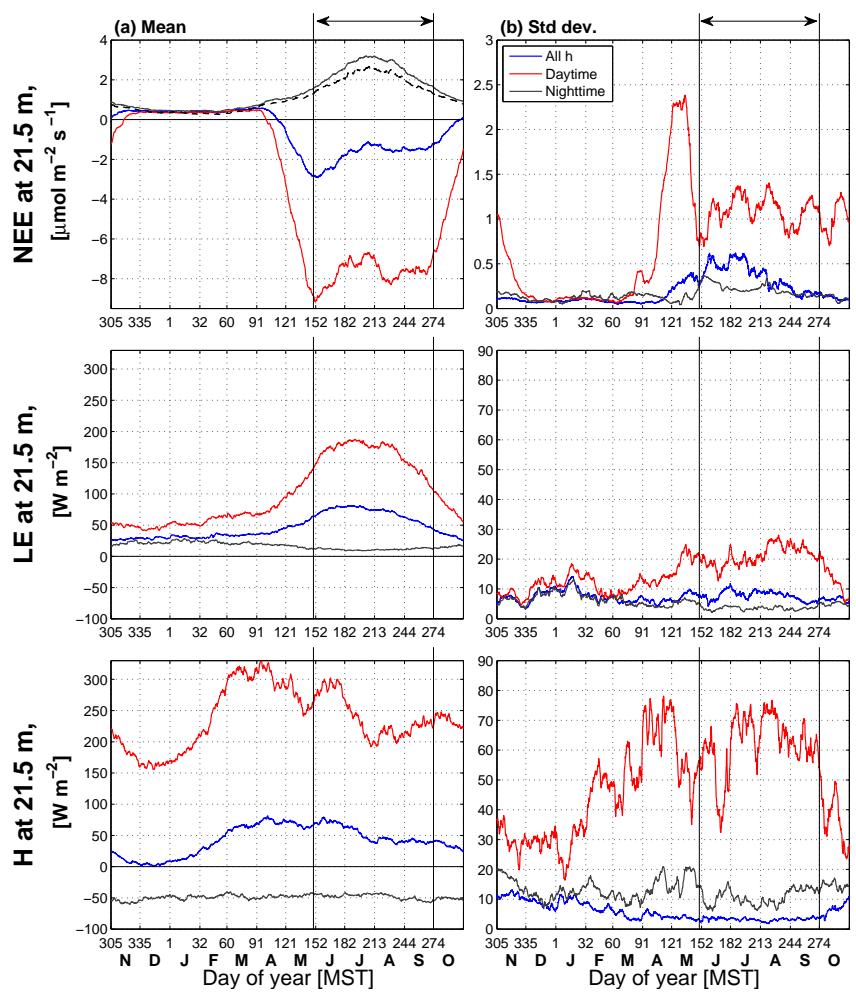

Figure 2. Fourteen-year (a) mean and (b) interannual standard deviation ( $n=14$ years) of (top) $\mathrm{CO}_{2}$ net ecosystem exchange NEE, (middle) latent heat flux LE, and (bottom) sensible heat flux $H$. To remove the effects of short-term changes due to weather each 30 min yearly time series is averaged with a 20 -day mean sliding window. In all panels, the statistics are calculated for all hours, daytime (10:00-14:00 MST), and nighttime (00:00-04:00 MST) periods following the legend in (b). In (a), nocturnal NEE calculated without the $u_{*}$ filter is shown as a dashed line. These data were collected between 1 November 1998 and 31 October 2012. Vertical lines with the arrows indicate the average warm-season period used for our study.

ing precipitation occurred on wWet days (i.e., Fig. 3b). The leaf wetness data reveal that, on average, dDry days had mean value less than 0.2 , while wet periods were closer to 0.8 (Fig. 3c). On wDry days there was a steady decrease in leaf wetness from midnight until the early morning hours. All precipitation states had a minimum in leaf wetness between around 08:00-10:00 MST which is likely related to a large-scale phenomena, such as the entrainment of dry air at the top of the boundary layer.

One obvious complication with the precipitation-related analysis is that the open-path instrumentation (e.g., sonic anemometers) are affected by water droplets, and do not work properly during heavy precipitation events which is why the percent of gap-filling periods for the fluxes increases on the wet days (Table 2). Though we do not have a way around this issue, we can only point out that the scalar measurements were not affected by precipitation, which provides some degree of insight. When we restricted the analysis to time periods without any gap-filled flux data, the results are similar to what we show here (see Appendix A5 for an example).

Over the next several sections we will examine how the diel cycle of the measurements (winds, soil properties, radiation, scalars, and fluxes) were affected by these different precipitation states. Because dDry conditions were the most common, we will typically describe the changes or differences relative to the dDry state.

\subsubsection{Wind, turbulence, vertical temperature profiles, and near-ground stability}

As mentioned in Sect. 2.1, the above-canopy wind direction at the site is primarily controlled by the large-scale mountainplain dynamics resulting in directions that were typically either upslope (from the east) or downslope (from the west). At night, the above-canopy winds were almost exclusively downslope with very little effect from precipitation except for a small occurrence of upslope flow during wWet conditions (i.e., Fig. 3a1). There was a more consistent flow direction in the early morning hours as demonstrated by the higher peak in the frequency distribution of Fig. 3a1 compared to Fig. 3a3. This suggests that the drainage flow became more persistent and consistent as the night progresses. During midday, wet conditions had a more frequent occurrence of upslope winds than downslope winds, whereas during dry days there was nearly an equal number of upslope and downslope winds (Fig. 3a2). This is to be expected because the upslope winds can trigger convection which (potentially) leads to precipitation.

The diel cycle of horizontal wind speed during dry conditions was characterized by a dip of about $1 \mathrm{~m} \mathrm{~s}^{-1}$ during the morning and evening transitions, with the evening transition having the lowest wind speed values (Fig. 3d). On dDry and wDry days the wind speed overnight (on average) increased from a minimum of around $2.5 \mathrm{~m} \mathrm{~s}^{-1}$ at 19:00 MST to a maximum of $4 \mathrm{~m} \mathrm{~s}^{-1}$ at 04:00 MST. During wet conditions the dip in wind speed during the transition periods did not exist and the mean wind speed on wWet days was typically smaller than other conditions throughout the diel cycle. Mechanical turbulence (characterized by the friction velocity $u_{*}$ ) generally follows the pattern of wind speed at night; however, during the daytime, the buoyancy generated by surface heating enhanced $u_{*}$ relative to nocturnal values (Fig. 3e). In dDry conditions the maximum variability in $U$ and $u_{*}$ was in the early morning (at around 06:00 MST) with less variability in the late afternoon and evening.

Near-ground vertical air temperature differences are considered because these help control the near-ground stability (Fig. 4d-f). In wWet conditions, the vertical air temperature difference was at a minimum during all times of the day. This is expected during the daytime because solar radiation, which warms the canopy and ground to create the air-surface tem- 

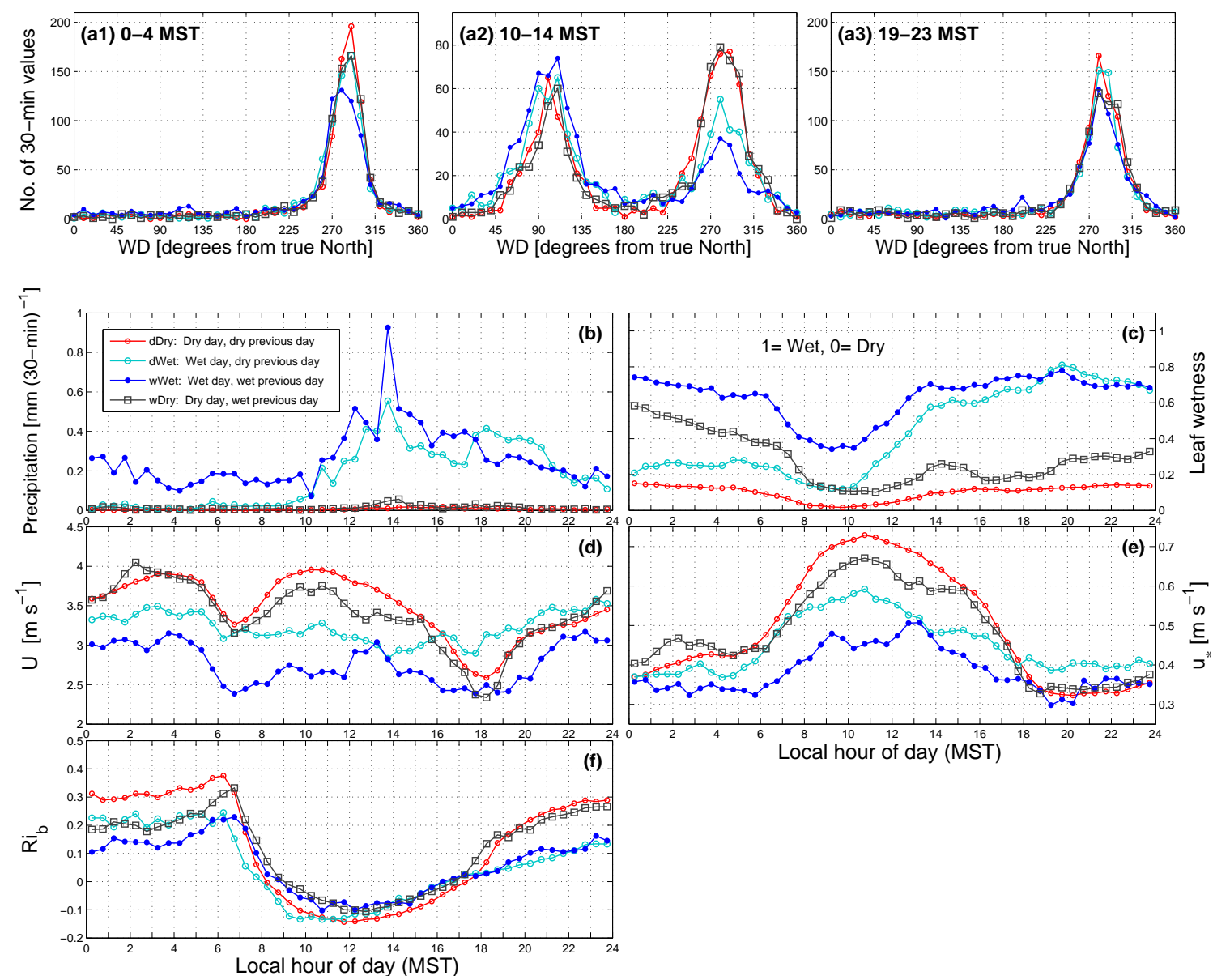

Figure 3. Frequency distributions of wind direction WD for different precipitation states for (a1) nighttime (00:00-04:00 MST) (a2) mid-day (10:00-14:00 MST), and (a3) late evening (19:00-23:00 MST) periods. Because there are a different number of 30 min periods within each precipitation state, the frequency distributions were created by randomly selecting 800 values for each precipitation state. Below (a1-a3), the mean warm-season diel cycle of (b) precipitation, (c) leaf wetness, (d) $21.5 \mathrm{~m}$ horizontal wind speed $U$, (e) $21.5 \mathrm{~m}$ friction velocity $u_{*}$, and (f) bulk Richardson number $\mathrm{Ri}_{\mathrm{b}}$ are shown. These composites are from $30 \mathrm{~min}$ data during the warm season between years 1999 and 2012. For all panels, each line represents a different precipitation state as shown in the legend of panel (b).

perature differences, was reduced on wWet days (radiation will be discussed in Sect. 3.2.4). In wDry conditions during daytime, the mid-canopy was about $1^{\circ} \mathrm{C}$ warmer than the air near the ground (Fig. 4e). This stable layer in the lower canopy did not exist in any other conditions and we presume this state was due to a combination of strong net radiation (which warmed the canopy) combined with evaporation near the ground (which cooled the ground surface). The soil during a wDry day would have recently experienced rain, providing a source of liquid water for evaporation within the soil. We also note that temperature differences during dDry days were the largest of all precipitation states for the three periods shown in Fig. 4d-f.

To combine the effects of wind speed and temperature differences on atmospheric stability, the bulk Richardson number $\mathrm{Ri}_{\mathrm{b}}$ is also considered (Fig. 3f). Following the evening transition, dry conditions tended to result in a more stable atmosphere $\left(\mathrm{Ri}_{\mathrm{b}}>0.2\right)$ than that of wet conditions $\left(\mathrm{Ri}_{\mathrm{b}}<\right.$ $0.1)$. This suggests that there should be larger vertical scalar differences (i.e., less vertical mixing) during the late evening period of dry days.

\subsubsection{Atmospheric scalars $\left(T_{a}, q\right)$, soil temperature, soil moisture, and soil heat flux}

We now consider how air temperature and humidity change over the diel cycle. dDry conditions were associated with slightly higher barometric pressure (Fig. 5a), relatively warmer air temperatures (Fig. 5c), a drier atmosphere (Fig. 5e), warmer and drier soils (Fig. 5b and d), and larger $10 \mathrm{~cm}$ soil heat fluxes (Fig. 5f). Barometric pressure had a mid-morning and evening peak that existed for all precipitation states which are created by thermal tides within the atmosphere (e.g., Lindzen and Chapman, 1969). The variables for dDry days generally had smaller variability com- 

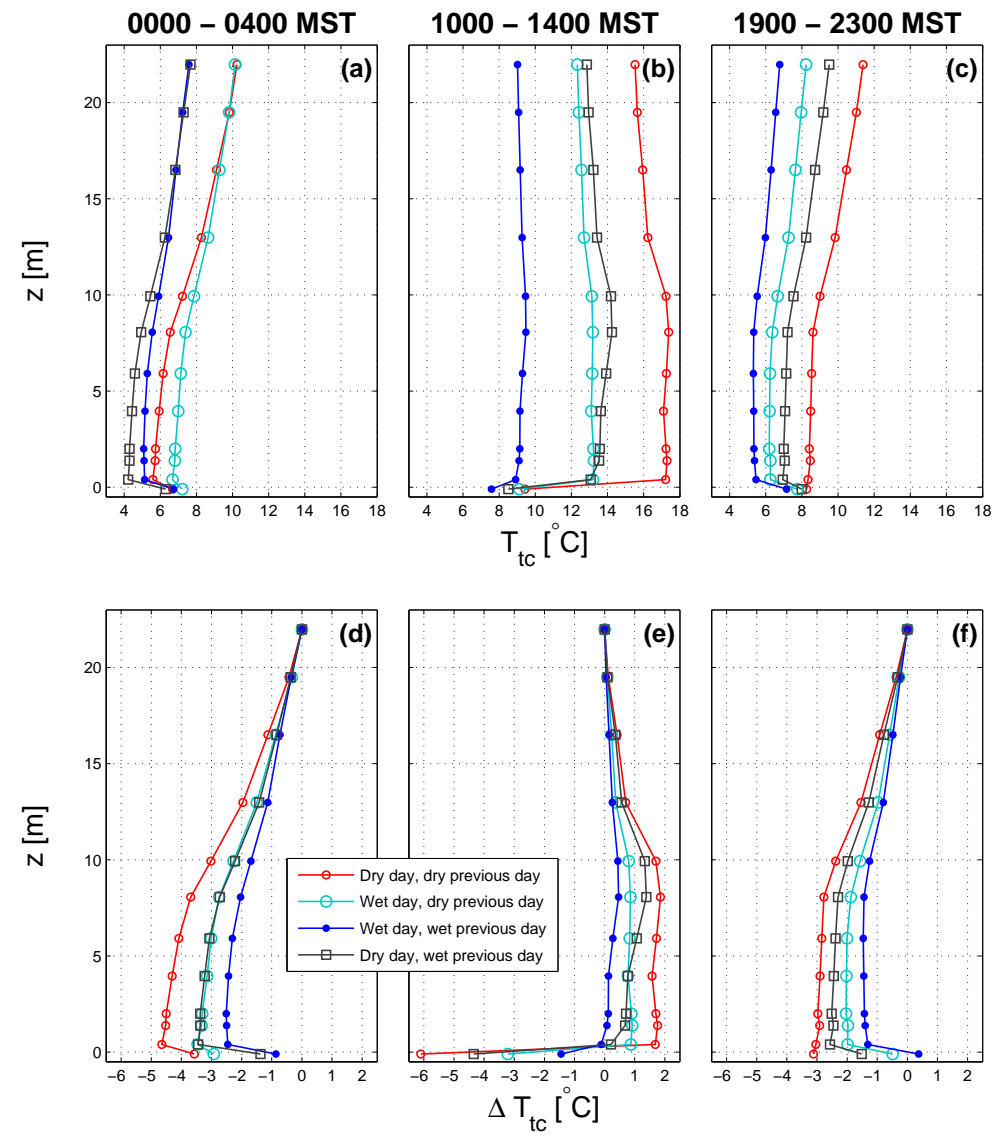

Figure 4. Vertical profiles of mean warm-season thermocouple air temperature $T_{\mathrm{tc}}$ and soil temperature $T_{\text {soil }}$ (at a depth of $5 \mathrm{~cm}$ ) for (left) nighttime (00:00-04:00 MST), (middle) mid-day (10:00-14:00 MST), and (right) late evening (19:00-23:00 MST). The upper row is the absolute temperature, while the bottom row is the temperature difference relative to the highest level ( $21.98 \mathrm{~m})$. Each line represents a different precipitation state as shown in the legend. These measurements are from the warm season in years 2006-2012.

pared to any of the other conditions with the one exception being a high variability in VPD during the dDry afternoon and evening period (Burns et al., 2015). In contrast to dDry days, mean conditions during wWet days were associated with (relatively) lower barometric pressure and cooler, wetter conditions in the atmosphere and soil.

For wWet days, the soil moisture content (VWC) increased by over $50 \%$ and $T_{\text {soil }}$ dropped by around $2{ }^{\circ} \mathrm{C}$ relative to dDry conditions (Table 3 and Fig. $5 b$ and d). The timing of precipitation within the diel cycle is important. For example, on the morning of dWet days, $T_{\text {soil }}$ was about $1{ }^{\circ} \mathrm{C}$ larger than in other conditions because on dWet days the rain occurred primarily in the afternoon, not the morning (i.e., Fig. 3b). In fact, $21.5 \mathrm{~m}$ air temperature on the morning of dWet days was nearly the same as that of dDry days (Fig. 5c). The main effect of precipitation on the deep-soil heat flux was between the hours of 11:00 and 18:00 MST, where $G_{\text {plate }}$ in dDry conditions had a peak of $20 \mathrm{~W} \mathrm{~m}^{-2}$ while in wWet conditions the peak was less than $10 \mathrm{~W} \mathrm{~m}^{-2}$ (Fig. 5f). At night, $G_{\text {plate }}$ was similar for all precipitation states suggesting that either the deeper $(10 \mathrm{~cm})$ soil was protected from the effect of changes in nocturnal net radiation by the overlying canopy and soil or else the changes in $R_{\text {net }}$ were small enough that the deep soil temperature was not dramatically affected. Though the soil heat flux peaked at around mid-day, the $5 \mathrm{~cm}$ soil temperature peaked two hours later at around 14:00 MST.

If plots for each precipitation condition are arranged in the order of dDry, dWet, wWet, and wDry days, the characteristics of a composite summertime cold-front passing the tower can be approximated (Fig. 6). Classical cold-front systems over flat terrain are associated with pre-frontal wind shifts and pressure troughs (e.g., Schultz, 2005). Mountains, however, have a large impact on the movement of air masses and can considerably alter the classical description of frontal passages (e.g., Egger and Hoinka, 1992; Whiteman, 2000). Our classification of the composite plots as a "frontal passage" is simply because there was colder air present at the site during the dWet and wWet periods. For example, during dDry days the $21.5 \mathrm{~m}$ air temperature was around $5^{\circ} \mathrm{C}$ greater than $T_{\text {soil }}$ (Fig. 6b1). As the composite "front" passed by the tower 


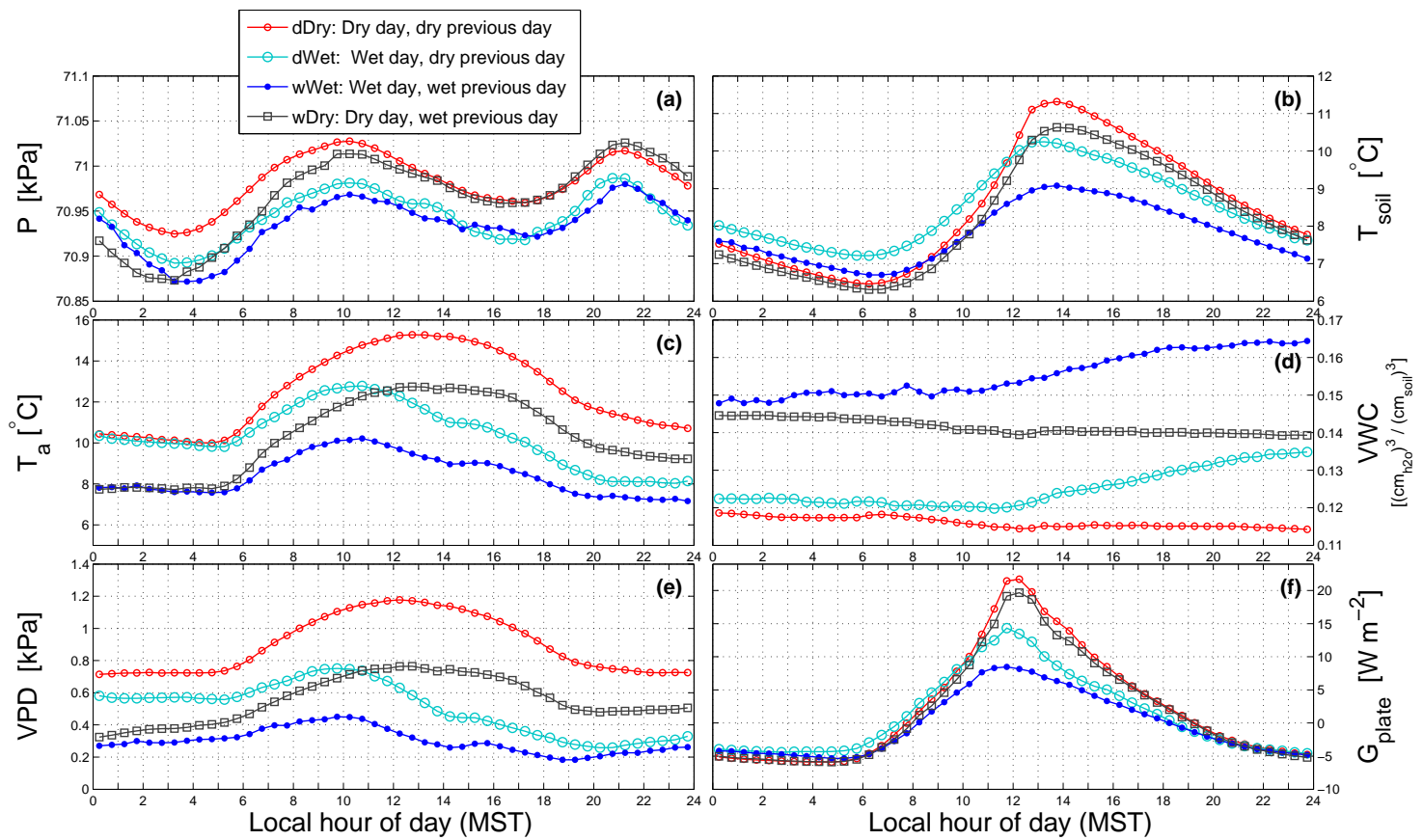

Figure 5. The mean warm-season diel cycle of (a) barometric pressure $P$, (b) $5 \mathrm{~cm}$ soil temperature $T_{\text {soil }}$, (c) $21.5 \mathrm{~m}$ air temperature $T_{\mathrm{a}}$,

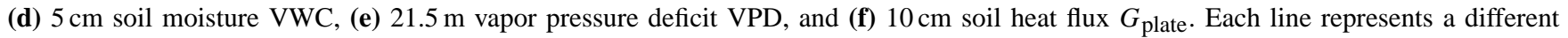
precipitation state as shown in the legend.
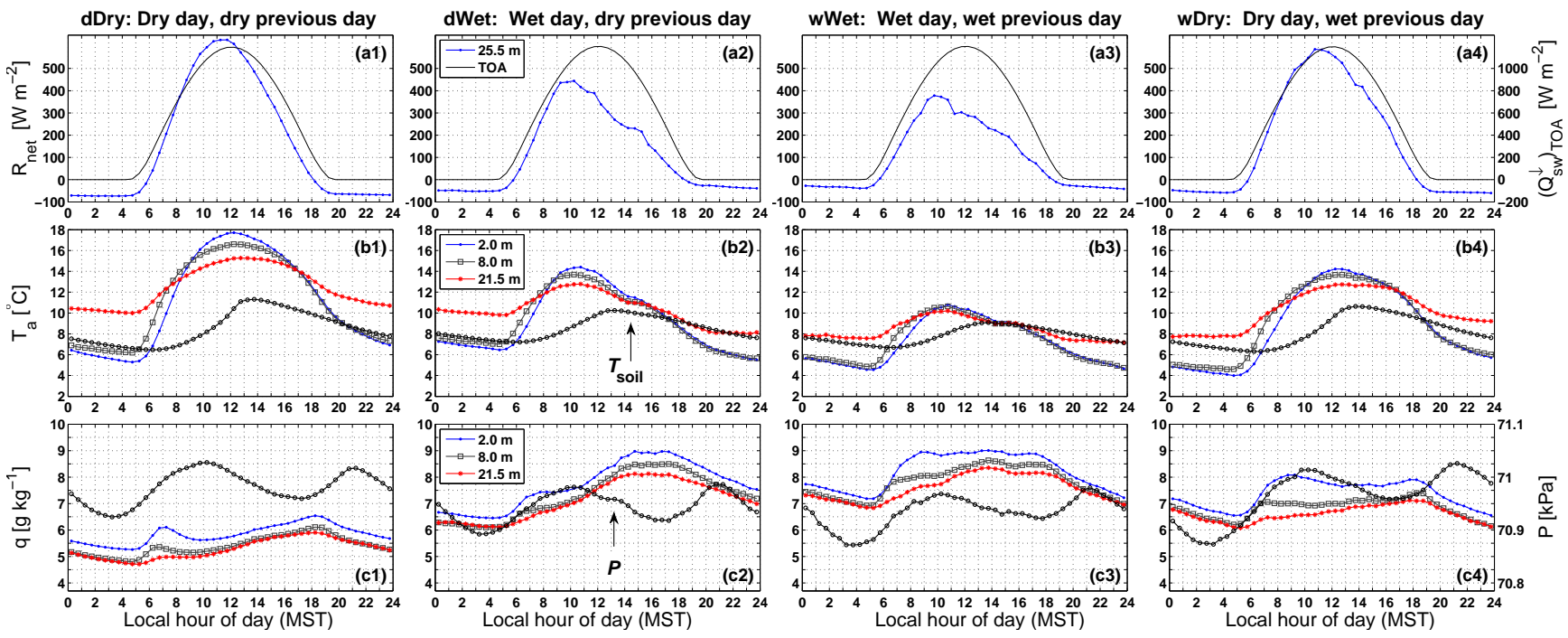

Figure 6. The warm-season mean diel cycle of (a1-a4) net radiation $R_{\text {net }}$ (left-hand axis) and top-of-the-atmosphere incoming shortwave radiation $\left(Q_{\mathrm{SW}}^{\downarrow}\right)$ TOA (right-hand axis), (b1-b4) air and soil temperature $T_{\mathrm{a}}, T_{\text {soil }}$, and (c1-c4) specific humidity $q$ and barometric pressure $P$. Within each column, the data are separated into diel periods based on whether significant rain occurred on that day. A "wet" day has a total daily precipitation of at least $3 \mathrm{~mm}$ (see text for further details). The legend in the 2nd column applies to all panels within each row.

(i.e., dWet and wWet days) $21.5 \mathrm{~m} T_{\mathrm{a}}$ dropped to near $T_{\text {soil }}$ (Fig. 6b2 and b3) and specific humidity increased by $\approx 50 \%$ (Fig. 6c2 and c3). After the frontal passage (i.e., wDry days), the $21.5 \mathrm{~m}$ air temperature returned to being higher than the soil temperature (Fig. 6b4). Specific numerical values for each precipitation state are provided in Table 3. 
Table 3. Daytime and nighttime statistics of selected variables for different precipitation conditions.

\begin{tabular}{|c|c|c|c|c|c|c|c|c|c|c|c|c|c|c|}
\hline \multirow[b]{2}{*}{ Variable } & \multirow[b]{2}{*}{ Symbol } & \multirow{2}{*}{$\begin{array}{r}\text { Sensor } \\
\text { height } \\
(\mathrm{cm})\end{array}$} & \multicolumn{4}{|c|}{ Night (00:00-04:00 MST) } & \multicolumn{4}{|c|}{ Daytime (10:00-14:00 MST) } & \multicolumn{4}{|c|}{ Evening (19:00-23:00 MST) } \\
\hline & & & dDry & dWet & wWet & wDry & dDry & dWet & wWet & wDry & dDry & dWet & wWet & wDry \\
\hline \multicolumn{15}{|l|}{ Primary measurements } \\
\hline Precipitation & Precip & 1050 & 0.002 & 0.017 & 0.201 & 0.010 & 0.007 & 0.288 & 0.401 & 0.018 & 0.006 & 0.264 & 0.213 & 0.008 \\
\hline Net radiation & $R_{\text {net }}$ & 2550 & -71.7 & -53.0 & -33.3 & -52.2 & 582.2 & 349.3 & 286.8 & 528.2 & -64.7 & -29.7 & -30.3 & -55.5 \\
\hline $\begin{array}{l}\text { Photosynthetically } \\
\text { active radiation }\end{array}$ & PAR & 2550 & 0 & 0 & 0 & 0 & 1408.4 & 865.6 & 715.8 & 1273.4 & 0 & 0 & 0 & 0 \\
\hline Barometric pressure & $P$ & 1050 & 70.97 & 70.92 & 70.93 & 70.97 & 70.97 & 70.92 & 70.93 & 70.97 & 70.97 & 70.92 & 70.93 & 70.97 \\
\hline \multirow[t]{2}{*}{ Air temperature } & $T_{\mathrm{a}}$ & 2150 & 10.0 & 9.7 & 7.0 & 7.3 & 14.8 & 11.7 & 8.9 & 11.9 & 11.1 & 7.8 & 6.8 & 9.3 \\
\hline & & 200 & 5.7 & 6.6 & 4.8 & 4.1 & 17.1 & 13.0 & 9.4 & 13.2 & 8.4 & 6.1 & 5.3 & 6.8 \\
\hline \multirow{3}{*}{$\begin{array}{l}\text { Thermocouple } \\
\text { temperature, } \\
\text { Vertical difference }\end{array}$} & $T_{\mathrm{tc}}$ & 2198 & 10.2 & 10.1 & 7.6 & 7.7 & 15.5 & 12.3 & 9.0 & 12.9 & 11.4 & 8.2 & 6.8 & 9.5 \\
\hline & & 40 & 5.6 & 6.7 & 5.1 & 4.2 & 17.2 & 13.2 & 8.9 & 13.1 & 8.3 & 6.2 & 5.5 & 6.9 \\
\hline & $\Delta T_{\mathrm{tc}}$ & $(2198-40)$ & 4.65 & 3.46 & 2.46 & 3.45 & -1.69 & -0.87 & 0.11 & -0.21 & 3.04 & 1.98 & 1.31 & 2.57 \\
\hline Soil temperature & $T_{\text {soil }}$ & -5 & 6.8 & 7.4 & 6.9 & 6.4 & 9.6 & 9.2 & 8.1 & 8.7 & 8.4 & 7.8 & 7.4 & 8.0 \\
\hline Soil heat flux & $G_{\text {plate }}$ & -10 & -5.6 & -4.2 & -4.6 & -5.5 & 17.0 & 11.5 & 7.4 & 15.3 & -2.6 & -3.1 & -3.2 & -2.9 \\
\hline $\begin{array}{l}\text { Volumetric } \\
\text { water content }\end{array}$ & VWC & -5 & 0.118 & 0.122 & 0.149 & 0.144 & 0.115 & 0.121 & 0.153 & 0.140 & 0.115 & 0.133 & 0.163 & 0.140 \\
\hline Wind speed & $U$ & 2150 & 3.8 & 3.4 & 3.0 & 3.7 & 3.8 & 3.1 & 2.8 & 3.5 & 3.2 & 3.2 & 2.7 & 3.1 \\
\hline \multirow{3}{*}{$\begin{array}{l}\mathrm{CO}_{2} \text { dry mole } \\
\text { fraction, }\end{array}$} & $\chi_{\mathrm{c}}$ & 2150 & 389.9 & 390.8 & 392.7 & 390.6 & 385.3 & 386.8 & 387.1 & 386.0 & 390.5 & 391.2 & 392.4 & 391.5 \\
\hline & & 100 & 424.1 & 425.8 & 426.8 & 421.9 & 388.8 & 391.9 & 395.2 & 391.6 & 421.9 & 415.0 & 417.7 & 423.5 \\
\hline & & 10 & 434.0 & 437.4 & 438.7 & 432.0 & 394.2 & 400.1 & 405.0 & 400.0 & 433.8 & 426.0 & 429.5 & 437.6 \\
\hline Vertical difference & $\Delta \chi_{\mathrm{c}}$ & $(2150-10)$ & -44.12 & -46.58 & -45.96 & -41.42 & -8.84 & -13.32 & -17.96 & -13.94 & -43.31 & -34.81 & -37.05 & -46.11 \\
\hline \multicolumn{15}{|l|}{ Calculated variables } \\
\hline \multirow[t]{2}{*}{ Specific humidity } & $q$ & 2150 & 4.9 & 6.2 & 7.0 & 6.4 & 5.2 & 7.4 & 7.9 & 6.6 & 5.5 & 7.4 & 7.3 & 6.5 \\
\hline & & 200 & 5.4 & 6.5 & 7.4 & 6.8 & 5.7 & 8.0 & 8.7 & 7.6 & 6.0 & 7.9 & 7.6 & 7.0 \\
\hline $\begin{array}{l}\text { Vapor pressure } \\
\text { deficit }\end{array}$ & VPD & 2150 & 0.7 & 0.54 & 0.25 & 0.34 & 1.1 & 0.61 & 0.31 & 0.71 & 0.74 & 0.28 & 0.20 & 0.47 \\
\hline Friction velocity & $u_{*}$ & 2150 & 0.40 & 0.38 & 0.34 & 0.41 & 0.70 & 0.55 & 0.47 & 0.63 & 0.33 & 0.37 & 0.31 & 0.33 \\
\hline $\begin{array}{l}\text { Bulk Richardson } \\
\text { number }\end{array}$ & $\mathrm{Ri}_{\mathrm{b}}$ & & 0.31 & 0.22 & 0.14 & 0.21 & -0.13 & -0.12 & -0.08 & -0.09 & 0.24 & 0.09 & 0.11 & 0.22 \\
\hline Sensible heat flux & $H$ & 2150 & -48.9 & -39.2 & -38.6 & -54.0 & 278.6 & 146.4 & 84.8 & 200.8 & -35.5 & -43.0 & -33.0 & -33.6 \\
\hline Latent heat flux & LE & 2150 & 9.1 & 8.6 & 17.4 & 22.7 & 169.7 & 123.1 & 118.2 & 192.4 & 9.2 & 24.7 & 18.4 & 12.5 \\
\hline $\begin{array}{l}\text { Net ecosystem } \\
\text { exchange of } \mathrm{CO}_{2}\end{array}$ & NEE & 2150 & 2.5 & 2.6 & 2.6 & 2.5 & -7.9 & -6.6 & -5.6 & -8.5 & 3.0 & 2.9 & 2.8 & 2.9 \\
\hline
\end{tabular}

\subsubsection{Atmospheric $\mathrm{CO}_{2}$ dry mole fraction}

For $\mathrm{CO}_{2}$ dry mole fraction $\chi_{\mathrm{c}}$, we found that above-canopy $\chi_{\mathrm{c}}$ was largest during wWet conditions and lowest in dDry conditions with a fairly consistent difference of around 2$3 \mu \mathrm{mol} \mathrm{mol}^{-1}$ across the entire diel cycle (Fig. 7a). We initially considered this to be an artifact of dilution due to boundary layer height differences (e.g., Culf et al., 1997); however, we ruled this out because the difference was fairly consistent throughout the day and night when boundary layer heights change dramatically. We confirmed that similar $\chi_{\mathrm{c}}$ differences between precipitation states existed using $\mathrm{CO}_{2}$ measured above tree-line on Niwot Ridge about $3.5 \mathrm{~km}$ northwest of the US-NR1 tower (Stephens et al., 2011) (results not shown). Since our analysis uses a composite which approximates a cold-front passage, there is an influence of large-scale weather systems on the overall atmospheric $\mathrm{CO}_{2}$ magnitude (e.g., Miles et al., 2012; Lee et al., 2012). This suggests that the dependence of above-canopy $\chi_{c}$ on the precipitation state was due to either the composition of large-scale air masses or subsidence/convergence caused by high/low barometric pressure.

Within the canopy, this same precipitation-dependent pattern existed in the morning and during the daytime, however, in the evening, $\chi_{c}$ in dry conditions was about 5$8 \mu \mathrm{mol} \mathrm{mol}^{-1}$ larger than $\chi_{\mathrm{c}}$ in wet conditions (Fig. 7bc). These differences clearly show up in a vertical $\chi_{c}$ profile (Fig. 8c). To avoid the confounding factor of synoptic weather systems, the lower panels in Fig. 8 show the vertical $\chi_{\mathrm{c}}$ differences $\left(\Delta \chi_{\mathrm{c}}\right)$ relative to the top tower level (21.5 m a.g.1.). The mid-day $\Delta \chi_{\mathrm{c}}$ profile (Fig. 8e) shows a photosynthetic deficit of around $1 \mu \mathrm{mol} \mathrm{mol}^{-1}$ in the midcanopy due to vegetative uptake of $\mathrm{CO}_{2}$ which is consistent with previous studies at the site (Bowling et al., 2009; Burns et al., 2011). In the nighttime hours (00:00-04:00 MST) the different precipitation states did not affect the $\Delta \chi_{\mathrm{c}}$ profile (Fig. $8 \mathrm{~d}$ ) which contrasts with the late evening $\Delta \chi_{\mathrm{c}}$ profile that shows a difference of around $5-9 \mu \mathrm{mol} \mathrm{mol}^{-1}$ between wet and dry conditions within the lower canopy (Fig. 8f). 


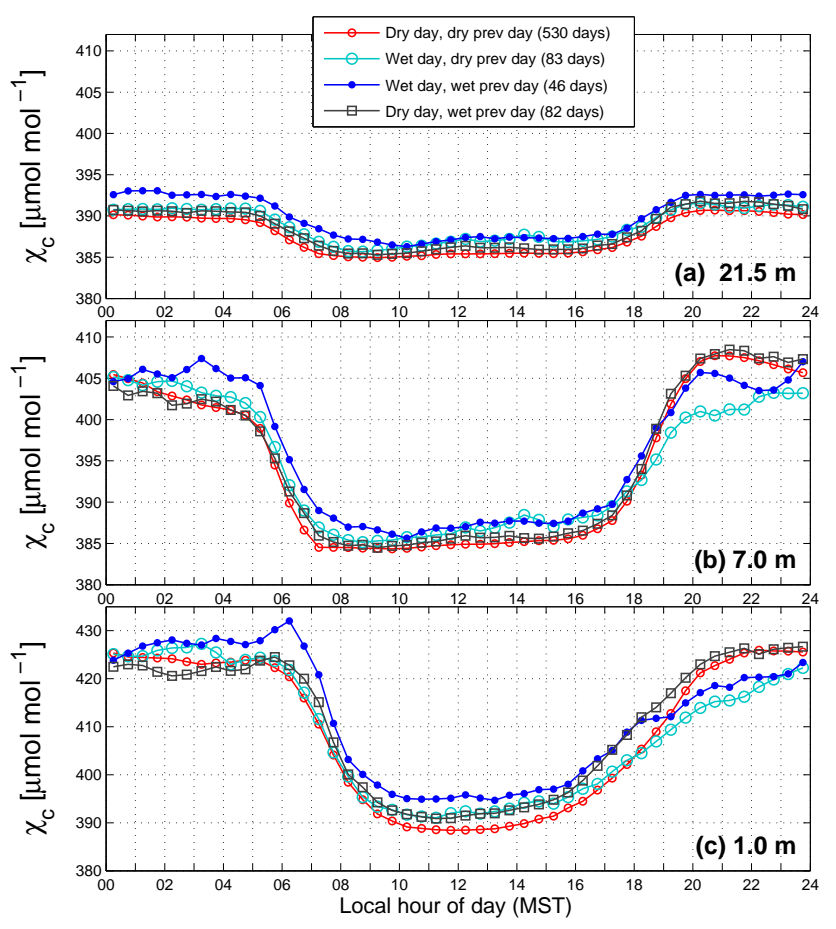

Figure 7. The warm-season mean diel cycle of $\mathrm{CO}_{2}$ mole fraction $\chi_{\mathrm{c}}$ at three different heights above the ground. Each line represents a different precipitation state as shown in the legend. These measurements are from the warm season in years 2006-2012.

Though synoptic barometric pressure changes have recently been suggested as a mechanism for enhancing the exchange of deep-soil $\mathrm{CO}_{2}$ with the atmosphere (e.g., SánchezCañete et al., 2013), the larger $\Delta \chi_{c}$ differences in dry conditions are consistent with the near-ground atmospheric stability being larger during dry conditions (discussed in Sect. 3.2.1). Between 00:00 and 04:00 MST Rib was generally near or above 0.2 for both wet and dry conditions, whereas in the evening period on wet days $\mathrm{Ri}_{\mathrm{b}}$ was $\approx 0.1$. As shown in previous work at the US-NR1 site (e.g., Schaeffer et al., 2008a; Burns et al., 2011), $\Delta \chi_{c}$ differences have a transition region between weakly stable and strongly stable conditions that occurs at $\mathrm{Ri}_{\mathrm{b}} \approx 0.25$ which is nominally related to the change from a fully turbulent to non-turbulent flow. It appears that the stability in the early evening on wet days is such that the atmosphere was slightly unstable which enhanced the vertical mixing and reduced the vertical $\Delta \chi_{\mathrm{c}}$ differences. Furthermore, the controls on the stability between dWet and wWet days were slightly different. On dWet evenings, wind speed was slightly elevated (Fig. 3d) which resulted in less stable conditions. In contrast, on wWet evenings it was the reduced vertical temperature differences (Fig. 4f) that was the primary controlling factor in reducing the stability.
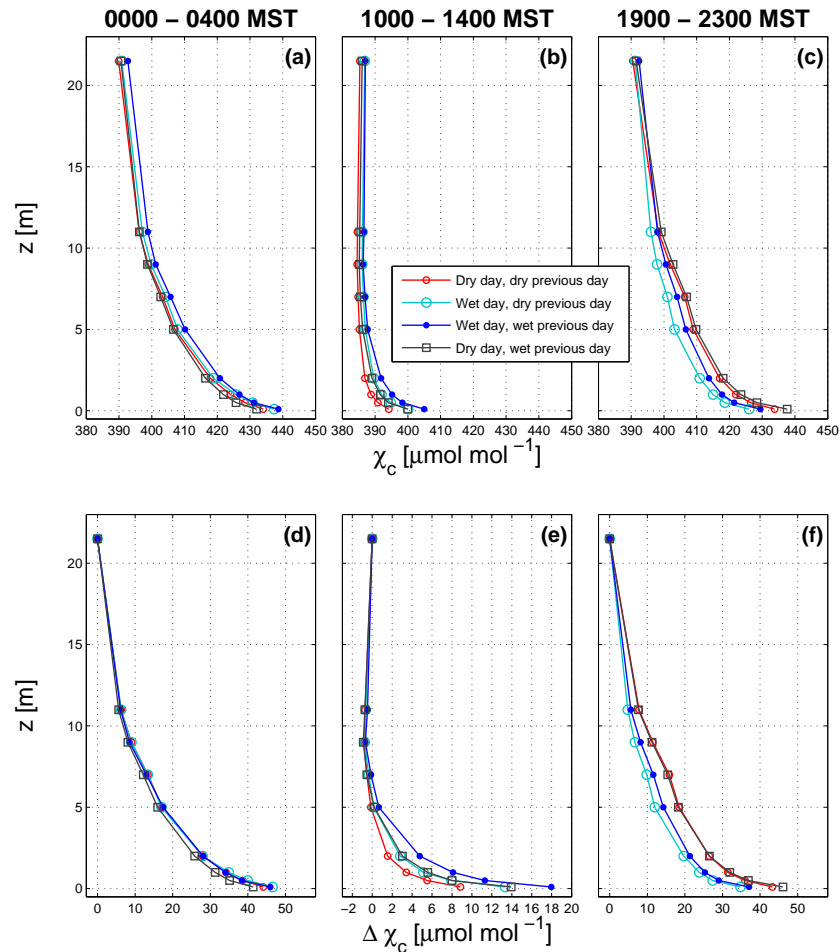

Figure 8. Mean vertical profiles of $\mathrm{CO}_{2}$ mole fraction $\chi_{\mathrm{c}}$ for (left) nighttime (00:00-04:00 MST), (middle) mid-day (10:00 14:00 MST), and (right) late evening (19:00-23:00 MST). The upper row is absolute $\chi_{\mathrm{c}}$ while the bottom row is the $\chi_{\mathrm{c}}$ difference relative to the highest level $(21.5 \mathrm{~m})$. Each line represents a different precipitation state as shown in the legend. These measurements are from the warm season in years 2006-2012.

\subsubsection{Net radiation and turbulent energy fluxes}

The full diel cycle of net radiation, the turbulent energy fluxes, NEE, and transpiration are shown in Fig. 9 where the diel cycles are arranged by dDry, dWet, wWet, and wDry conditions. The dDry conditions are repeated in each column to make comparison between conditions easier. In order to better quantify the impact of precipitation state on the fluxes, we also show a summary that only includes mean mid-day (Fig. 10, left-column) and late evening and nighttime values (Fig. 10, right-column). To make interpretation of the quantitative changes more accessible, each panel in Fig. 10 shows the fractional change from the maximum (or minimum) value within that panel. The mean values for each precipitation state are also listed in Table 3.

When precipitation occurred, cloudiness increased and net radiation at mid-day was reduced (Fig. 9a). dDry days had a mean mid-day value of nearly $600 \mathrm{~W} \mathrm{~m}^{-2}$ which decreased by around $50 \%$ to $300 \mathrm{~W} \mathrm{~m}^{-2}$ during wWet days, then recovered on wDry days to nearly $550 \mathrm{~W} \mathrm{~m}^{-2}$ (i.e., about $10 \%$ smaller than $R_{\text {net }}$ during dDry conditions; Fig. 10a1). 

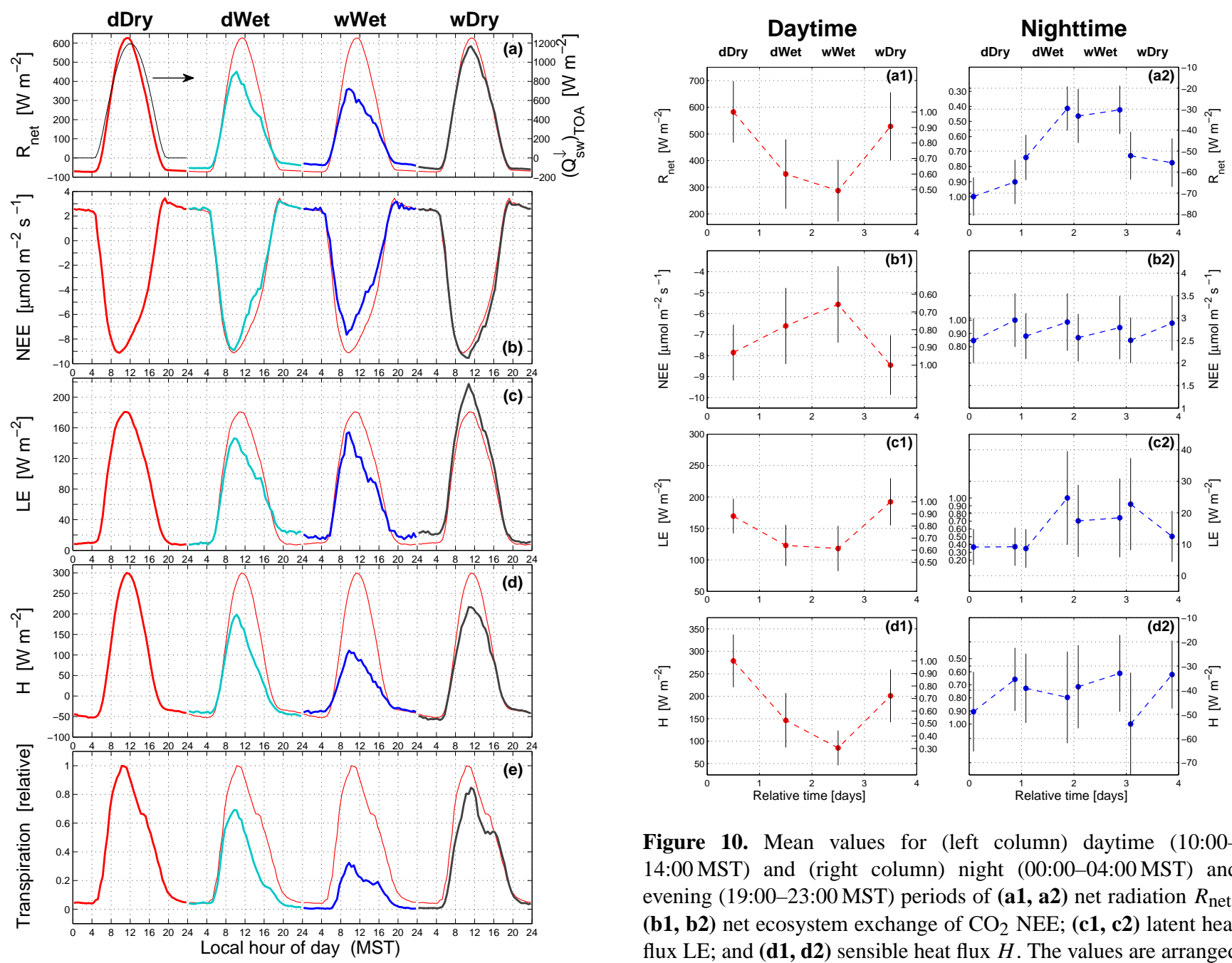

Figure 10. Mean values for (left column) daytime (10:0014:00 MST) and (right column) night (00:00-04:00 MST) and evening (19:00-23:00 MST) periods of (a1, a2) net radiation $R_{\text {net }}$; (b1, b2) net ecosystem exchange of $\mathrm{CO}_{2} \mathrm{NEE}$; (c1, c2) latent heat flux LE; and (d1, d2) sensible heat flux $H$. The values are arranged from left-to-right in the order of dDry, dWet, wWet, and wDry conditions. The vertical black lines represent the mean absolute deviation (MAD) of the $30 \mathrm{~min}$ data within that particular category and time period. The numerical values shown between the daytime and nighttime panels represent the fractional change relative to the largest (or smallest) data value within the panel. diel cycle is repeated in all columns as a red line. In (a), incoming shortwave radiation at the top of the atmosphere $\left(Q_{\mathrm{SW}}^{\downarrow}\right)$ TOA is shown as a black line in the dDry column (using the right-hand axis). Transpiration is estimated from several pine trees near the US-NR1 tower during the summers of 2004, 2006, and 2007. For all other variables, the diel cycle is calculated from $30 \mathrm{~min}$ measurements between years 1999 and 2012.

At night, though the absolute value of the mean net radiation was an order of magnitude smaller than the daytime values, the fractional changes and pattern of nocturnal $R_{\text {net }}$ due to different precipitation states (Fig. 10a2) were similar to those of mid-day $R_{\text {net }}$ (Fig. 10a1). If we assume that wet nights were cloudier than dry nights, the radiative surface cooling on clear nights was around $-70 \mathrm{~W} \mathrm{~m}^{-2}$, while that of cloudy nights was closer to $-30 \mathrm{~W} \mathrm{~m}^{-2}$. The reduc-

tion of the magnitude of $R_{\text {net }}$ on wet nights was primarily due to changes in cloud cover as well as changes to the turbulent fluxes.

Sensible heat flux during mid-day had a similar pattern to net radiation, with a large decrease in $H$ (by $\approx 70 \%$ ) between dDry and wWet conditions, followed by a return toward dDry $H$ on wDry days (Fig. 10d1). In contrast, latent heat flux followed a different pattern - the largest mean mid-day LE occurred on a wDry day with a value of around $200 \mathrm{~W} \mathrm{~m}^{-2}$, which was around $15 \%$ larger than mid-day LE on dDry days (Figs. 9c, 10c1). The extra energy used by LE (coupled with slightly lower $R_{\text {net }}$ values on wDry days) explains why mid-day $H$ only recovered to within $80 \mathrm{~W} \mathrm{~m}^{-2}$ (or $30 \%$ ) of dDry $H$ as dictated by the SEB (Eq. 1) and shown in Fig. 9d. 

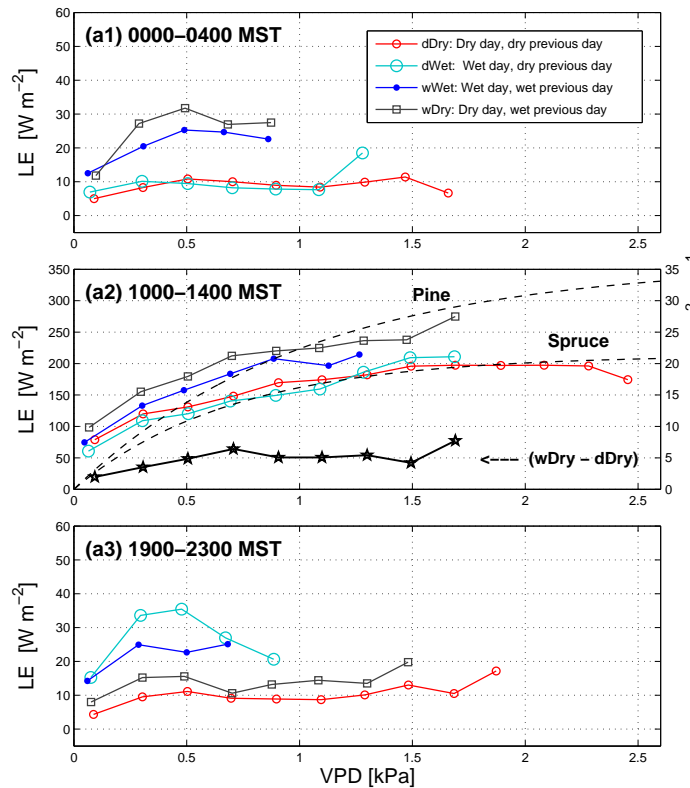
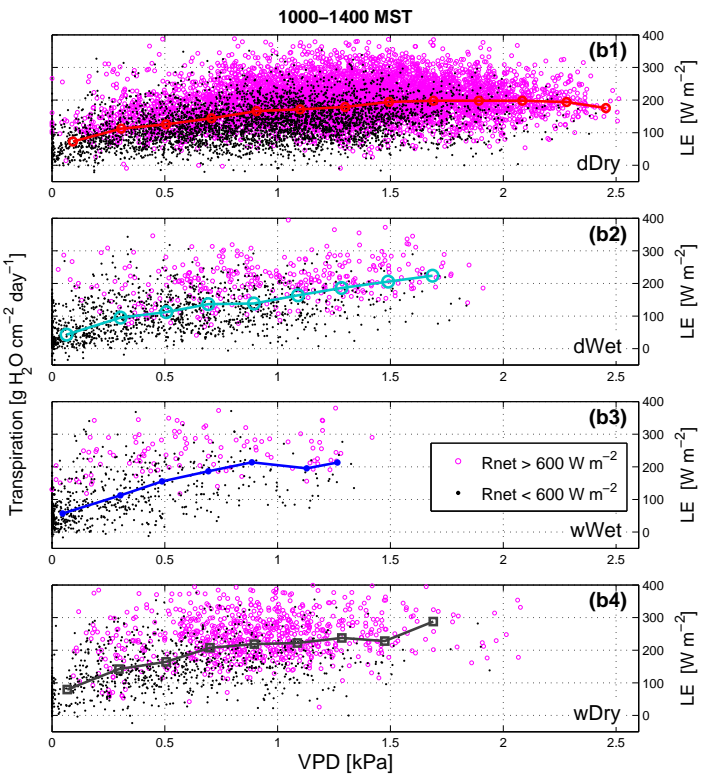

Figure 11. The (left column) binned 21.5 m latent heat flux LE vs. 21.5 m vapor pressure deficit VPD for (a1) night (00:00-04:00 MST), (a2) daytime (10:00-14:00 MST), and (a3) evening (19:00-23:00 MST) periods. Each line represents a different precipitation state as shown in the legend. In (a2), the dashed black lines are the empirical exponential fits of transpiration per unit sapwood area vs. VPD for 2006 as determined by $\mathrm{Hu}$ et al. (2010b) for pine and spruce trees (using the right-hand axis). Also, the difference in LE between wDry and dDry conditions is shown as a solid black line. As an example of the variability in the binned data, the right-column panels show the 30 min daytime data used to create the binned daytime lines (i.e., corresponding to what is shown in panel a2). The right-column panels are for (b1) dDry, (b2) dWet, (b3) wWet, and (b4) wDry periods. In the scatter plots, the individual points are distinguished by $R_{\text {net }}$ as shown by the legend in (b3).

At night, latent heat flux cooled the surface and was strongly affected by changes in the precipitation state (Fig. 10c2) following a pattern similar to that of nocturnal $R_{\text {net }}$ (Fig. 10a2). Nocturnal sensible heat flux changed by around 30-40\% during the different precipitation states, but the pattern did not clearly follow that of either $R_{\text {net }}$ or LE (Fig. 10d2). At night, $H$ generally warms the surface (including the forest vegetation and other biomass) following the air-surface temperature gradient (i.e., similar to the vertical temperature differences shown in Fig. $4 \mathrm{~d}$ and f). In this way, $H$ acts to compensate for air-surface temperature differences that might be generated by the surface cooling effects of $R_{\text {net }}$ and LE. Even though the vertical air temperature differences were largest during dDry conditions (Fig. 4d and f) the largest sensible heat flux occurred during wDry periods between 00:00-04:00 MST (Fig. 10d2). This is exactly when LE was at a maximum (so evaporative cooling would be expected) and a close look at Fig. $4 \mathrm{f}$ reveals that the temperature difference between the air just above the ground and soil was larger in wDry conditions than dDry conditions. We should also note that what is shown in Fig. $4 \mathrm{~d}$ and $\mathrm{f}$ are vertical air temperature differences which serve as a surrogate for the actual difference between air temperature and the surface elements (i.e., tree branches, needles, boles, and the soil surface) (e.g., Froelich et al., 2011).

\subsubsection{The evaporative contribution to $\mathrm{LE}$}

The increased LE values on wDry days was presumably due to evaporation of the intercepted liquid water present on vegetation and in the soil. Because of the effect of temperature on saturation vapor pressure (and thus VPD) one cannot assume outright that nocturnal LE is representative of daytime evaporation (e.g., Brutsaert, 1982). To further explore this issue, we have plotted LE vs. VPD in Fig. 11 where we observe that nocturnal LE in dry conditions was $\approx 10 \mathrm{~W} \mathrm{~m}^{-2}$ with a weak dependence on VPD. The trend toward less evaporation in dDry conditions is due to a large soil resistance to evaporation when the soil/litter surface under a canopy is dry (Baldocchi and Meyers, 1991). This is consistent with there being a small, persistent baseline level of evaporation in dry conditions and we make an assumption that this level of evaporation is similar during the daytime. Therefore, in dDry conditions we can estimate that evaporation was $\approx 10 \mathrm{~W} \mathrm{~m}^{-2}$ and evapotranspiration was $\approx 170 \mathrm{~W} \mathrm{~m}^{-2}$ (based on mid-day LE, Fig. 10c1). This suggests that, on average, evaporation comprised about $6 \%$ of evapotranspiration in dry conditions.

Can we make a similar estimate of the evaporative contribution to LE as the canopy and soil are drying out? By comparing dDry and wDry conditions we make the following observations (1) mid-day LE in wDry conditions was 
larger than dDry conditions (Fig. 9c), (2) mid-day transpiration was relatively smaller in wDry conditions than dDry conditions (Fig. 9e), (3) net radiation in dDry and wDry conditions was similar (Fig. 9a), (4) soil moisture content was relatively high on wDry days (Fig. 5d), suggesting the presence of an available source of liquid water for evaporation, and (5) previous research of transpiration at the US-NR1 site (Turnipseed et al., 2009; Hu et al., 2010b) has shown that ecosystem-scale transpiration increases as VPD increases. We also observe that daytime LE follows a trend with VPD that is very similar to that of transpiration measured within the forest (as shown by the dashed black lines in Fig. 11a2). From (1) and (2) above, we can conclude that the daytime increase in wDry LE was primarily caused by an increase in evaporation, not transpiration. If we also consider how LE varied with VPD a rough estimate of daytime evaporation comes from the LE difference during dDry and wDry conditions (shown as the solid black line in Fig. 11a2). As the atmosphere becomes drier the LE difference increased from near $15 \mathrm{~W} \mathrm{~m}^{-2}$ to around $50 \mathrm{~W} \mathrm{~m}^{-2}$ where it flattens out in drier conditions (for VPD > 0.5). Therefore, following a rain event, daytime evaporation was somewhere between $15-50 \mathrm{~W} \mathrm{~m}^{-2}$, while mid-day evapotranspiration increased from 100 to $225 \mathrm{~W} \mathrm{~m}^{-2}$ (wDry line in Fig. 11a2). If we take the overall average of this ratio, it suggests that evaporation comprised between 15 and $25 \%$ of evapotranspiration as the forest transitioned from wet to dry conditions.

The partitioning of evapotranspiration for a forest is strongly dependent on the vegetation density and modeling efforts by Lawrence et al. (2007) suggest that, for a canopy density similar to that of the US-NR 1 forest (i.e., LAI $\approx 4$ ), transpiration should be around $80 \%$ of evapotranspiration. In a survey of 81 different studies from around the world, Schlesinger and Jasechko (2014) found that the ratio of transpiration to evapotranspiration in temperate coniferous forests have a typical range between 50 and $65 \%$. This is a large-scale estimate from the perspective of an overall water budget that does not include details such as a dependence of evapotranspiration on LAI or surface wetness (they also note that uncertainties in their estimates are large). For the spruce forest studied by Staudt et al. (2011) with $\mathrm{LAI} \approx 4.8$, they found that transpiration accounted for about $90 \%$ of total evapotranspiration (in generally dry conditions). Based on lysimeter measurements of evaporation, it was found that transpiration comprised about $95 \%$ of total evapotranspiration during the growing season in a boreal aspen forest (Blanken et al., 2001). The values we determined are within a similar range to these previous studies.

Our results are mean estimates and the variability around these mean values can be large (e.g., Burns et al., 2015). Some of this variability is due to the random nature of turbulence in the atmosphere, whereas some can be explained by differences in net radiation, atmospheric stability, air temperature, and stomatal control. For example, in the scatter plots of Fig. 11b1-b4, the LE data with larger $R_{\text {net }}$ values gener- ally fall above the bin-averaged line that is drawn through the cloud of data points.

We also observed that increased LE lasted throughout a wDry day until around 18:00 MST when LE came within around $10 \%$ of LE in dDry conditions (Figs. 9c and 11a3). This suggests that the evaporative effect lasted at least $18 \mathrm{~h}$ following a significant precipitation event. Central to our calculations is the assumption that LE at night was primarily evaporation. Some evidence exists that the needle stomates opening at night combined with cuticular water loss could lead to small amounts of nocturnal transpiration (e.g., Novick et al., 2009). If this occurred at US-NR1, it is likely a small effect which is further discussed by Turnipseed et al. (2009).

\subsubsection{Net ecosystem exchange of $\mathrm{CO}_{2}$ (NEE)}

As one would expect, the magnitude of daytime NEE was reduced during wet conditions due to decreased photosynthetically active radiation (PAR) which is shown as a decrease in $R_{\text {net }}$ in Fig. 9a. The ratio between mid-day PAR and $R_{\text {net }}$ was similar for all precipitation states (Table 3 ) and we will use $R_{\text {net }}$ as a surrogate for PAR in our discussion. The wDry days were when the forest was most effective at assimilating $\mathrm{CO}_{2}$ and the magnitude of NEE increased by over $3 \mu \mathrm{mol} \mathrm{m}^{-2} \mathrm{~s}^{-1}$ $(\approx 30 \%)$ between wWet and wDry days (Fig. 10b1).

Nocturnal NEE was not affected very much (less than $10 \%$ ) by changes in the precipitation state and any effect was overshadowed by the difference between NEE in the late evening compared to the early morning (Figs. 9b and 10b2). Though the seasonal nocturnal ecosystem respiration signal was, at least for the seasonal scale, apparently captured at the $21.5 \mathrm{~m}$ measurement level (i.e., Fig. 2a), it appears that the effect of advection on the diel cycle is larger than any effect of precipitation.

The lack of any strong effect of precipitation on the flux of $\mathrm{CO}_{2}$ (NEE) compared to water vapor (LE) is perplexing because one would expect the turbulence to transport water vapor and $\mathrm{CO}_{2}$ in a similar manner. $\mathrm{A}$ few possible reasons for this difference are the following: (1) soil respiration at the US-NR1 site was not strongly affected by precipitation, (2) long dry periods are rare enough that the Birch effect (i.e., $\mathrm{CO}_{2}$ pulse following precipitation) did not have a large impact on the overall warm-season NEE statistics, (3) the measurement of NEE at $21.5 \mathrm{~m}$ was not accurately describing the soil respiration at the soil surface due to surface decoupling and/or other problems related to stable conditions (e.g., Mahrt, 1999; Staebler and Fitzjarrald, 2004; Finnigan, 2008; Aubinet, 2008; Thomas et al., 2013), (4) the difference in vertical location of these two scalar sources (e.g., liquid water evaporates from the vegetation surfaces as well as at the ground whereas respiration of $\mathrm{CO}_{2}$ occurs almost exclusively at the ground) caused differences in the sensitivity to precipitation (Edburg et al., 2012), or (5) an effect of the shorter atmospheric residence-time and larger background variability of water vapor compared to $\mathrm{CO}_{2}$ which affects the surface 
fluxes. Previous measurements (mostly during the daytime) of soil respiration $R_{\text {soil }}$ at US-NR1 with a manual chamber system by Scott-Denton et al. $(2003,2006)$ found that the dependence of soil respiration on soil moisture over a given summer was small. It has also been suggested by Huxman et al. $(2004,2003)$ that ecosystem respiration at the US-NR1 site is subject to controls from temperature and radiation as much as from precipitation (in contrast to an arid or semi-arid ecosystem such as a desert grassland where $R_{\text {eco }}$ is strongly dependent on precipitation). The $\mathrm{CO}_{2}$ pulse related to the Birch effect has been detected by eddy-covariance at a wide variety of ecosystems that are listed in the introduction. For the current study, the relevant results are the following: (i) the $21.5 \mathrm{~m}$ nocturnal NEE measurements were able to detect the increase in nocturnal ecosystem respiration over the warm season (Fig. 2a), and (ii) the nocturnal NEE was not strongly affected by precipitation (Fig. 10b2). This suggests that, at the seasonal/annual time scale, precipitation plays a minor role in modifying the contribution of ecosystem respiration to the above-canopy NEE for this subalpine ecosystem.

\subsection{Asymmetry in the diel cycle of net radiation and turbulent fluxes}

One other interesting aspect of the diel cycle is related to the timing of fluxes relative to solar noon. As one would expect, the top of the atmosphere radiation reached a maximum near 12:00 MST (Fig. 9a). In contrast, the maximums for composited $R_{\text {net }}, \mathrm{LE}$, and $H$ occurred at about 11:00 MST on dry days and 10:00 MST on wet days (Fig. 9a, c-d). For NEE, the peak uptake of $\mathrm{CO}_{2}$ was between 09:00 and 10:00 MST on both wet and dry days (Fig. 9b). The fact that the peak in the energy fluxes was different for wet and dry conditions suggests that clouds were affecting the composited diel cycle.

In Fig. 12 we further examine the role of clouds on the diel cycle by sub-dividing the dDry days into clear sky (dDryClear) and cloudy (dDry-Cloudy) days. Clear skies occurred on about $18 \%$ of the dDry days, and this is reflected by the fact that the dDry statistics closely follow those of dDryCloudy statistics. The peak in $R_{\text {net }}, \mathrm{LE}$, and $H$ during dDryClear days were all near 12:00 MST which was consistent with the timing of the maximum top of the atmosphere radiation.

On dDry-Clear days, $R_{\text {net }}$ was enhanced by an additional $30 \%$ compared to cloudy days (Fig. 12a). This enhanced incoming radiation was reflected by larger turbulent energy (LE and $H$ ) fluxes on dDry-Clear days (Fig. 12c-d). Consistent with the findings by Monson et al. (2002), the magnitude of NEE was slightly smaller on clear-sky days suggesting that the forest was taking up more $\mathrm{CO}_{2}$ when clouds were present (Fig. 12b). This result is primarily due to $\mathrm{CO}_{2}$ uptake by vegetation being most efficient under diffuse radiative conditions (e.g., Gu et al., 1999, 2002; Law et al., 2002; Wang et al., 2008). Further discussion is in Monson

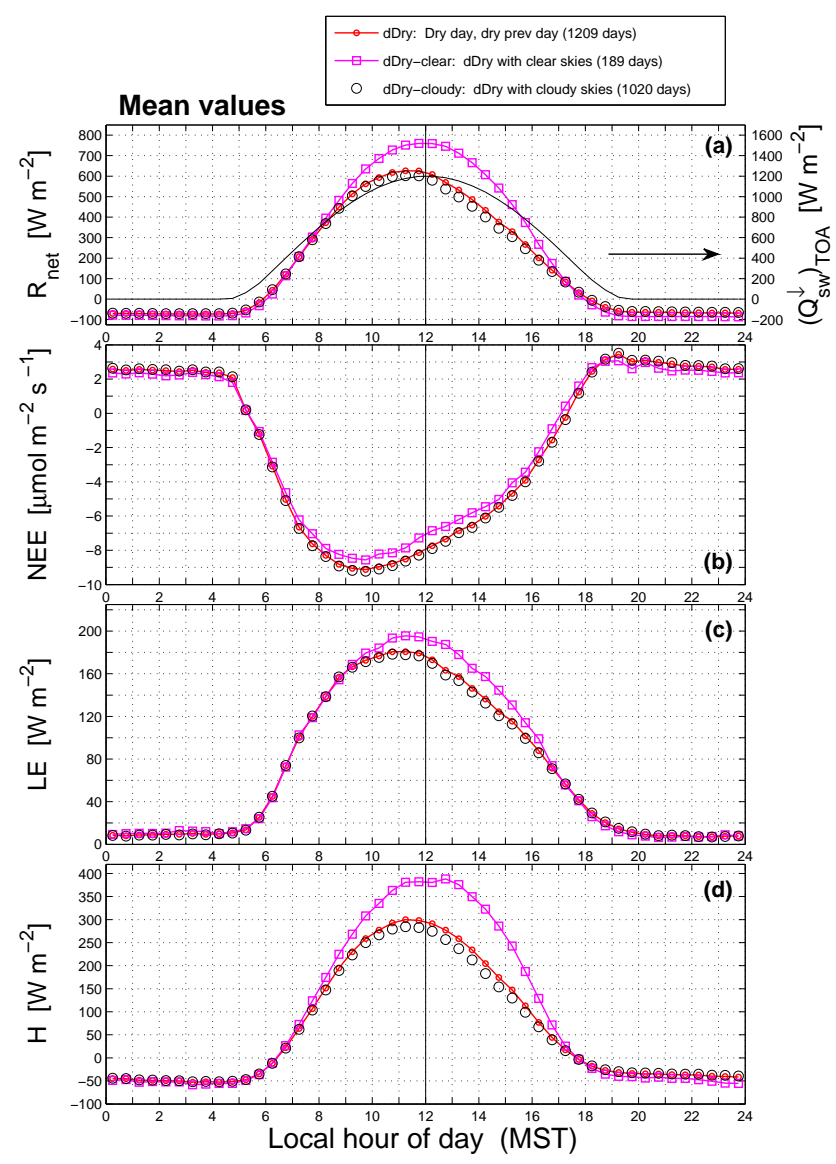

Figure 12. The mean warm-season diel cycle of (a) net radiation $R_{\text {net }}$ (left-hand axis) and top-of-the-atmosphere incoming shortwave radiation $\left(Q_{\mathrm{SW}}^{\downarrow}\right)_{\mathrm{TOA}}$ (right-hand axis, thin black line), (b) net ecosystem exchange of $\mathrm{CO}_{2} \mathrm{NEE}$, (c) latent heat flux LE, and (d) sensible heat flux $H$, for dDry conditions. This is the same as the dDry column in Fig. 9, except the data have been further separated into dDry-Clear and dDry-Cloudy conditions as specified by the legend. For further details see the caption of Fig. 9.

et al., 2002. If LE was completely controlled by stomates, one would expect that LE would follow NEE and be larger on dDry-Cloudy days. However, the effect of higher $R_{\text {net }}$ on clear days also affects LE (through the SEB equation) and drives it to slightly higher levels on dDry-Clear days.

\subsection{The surface energy balance (SEB) closure}

Though the individual components in the SEB balance equation (i.e., Eq. 1) were dramatically affected by precipitation (i.e., Fig. 10), the overall mean SEB closure fraction during mid-day was fairly consistent at around 0.9-1.1 (Fig. 13a1). This degree of energy closure is similar to that observed by previous research at the site (e.g., Turnipseed et al., 2002). It appears that wet conditions lead to values which are slightly above 1 and dry conditions are slightly below 1 . This sug- 

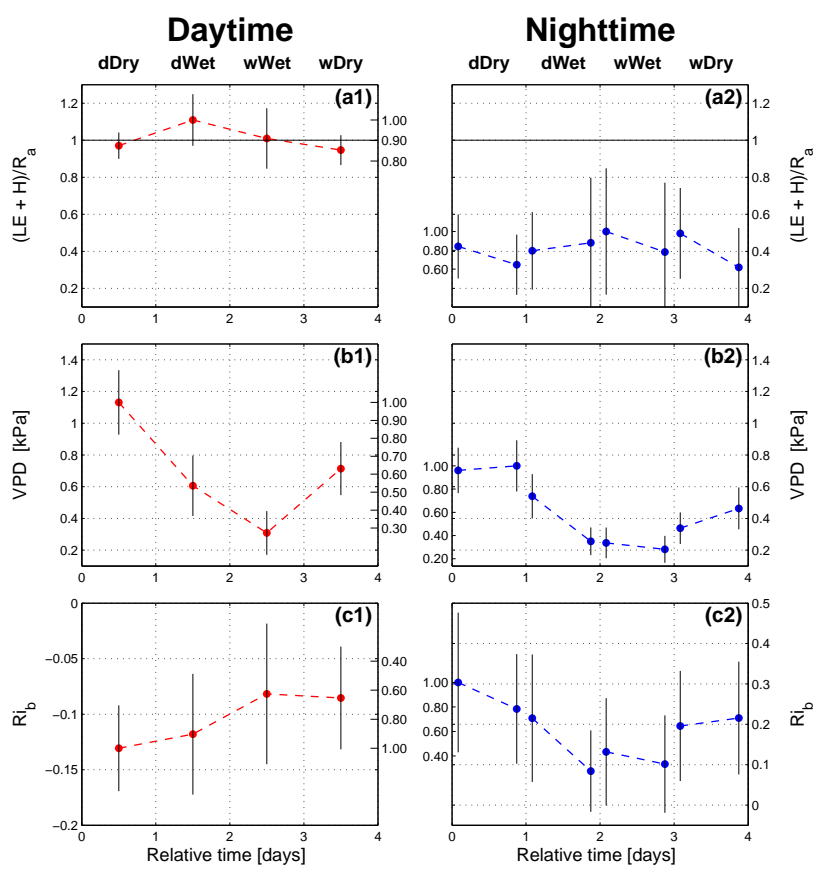

Figure 13. As in Fig. 10, showing (a1, a2) the surface energy balance closure fraction $(\mathrm{LE}+H) / R_{\mathrm{a}} ;(\mathbf{b 1}, \mathbf{b 2})$ vapor pressure deficit VPD; and (c1, c2) bulk Richardson number $\mathrm{Ri}_{\mathrm{b}}$.

gests that there could be some small effect of precipitation on the SEB closure.

The nighttime SEB closure during the evening hours (19:00-23:00 MST) was at around 0.3-0.4 while closure during the early morning hours (00:00-04:00 MST) was closer to $0.4-0.5$. Previous research has shown that these low nocturnal closure values are during periods of low winds that lead to large horizontal advection (Turnipseed et al., 2002; Burns et al., 2012). Any effect of precipitation on the SEB at night was overshadowed by differences related to the time of day. The effect of drainage flows on horizontal $\mathrm{CO}_{2}$ advection at US-NR1 have been summarized in previous studies (e.g., Sun et al., 2007; Yi et al., 2008), and our objective is to point out that the SEB closure improved after midnight, presumably because the wind speed and variability of mechanical turbulence increased. This result is consistent with the findings of Burns et al. (2011) that there is increased turbulence variability in the nocturnal boundary layer after around 23:00 MST. However, we have also reported (in Sect. 3.2.1) that stability tends to get stronger as the night progresses, especially in dDry conditions. Though outside the scope of the current study, our suspicion is that as the stability and wind speed increase during the night it leads to the formation of intermittent turbulent events caused by increased wind shear. In terms of precipitation, it is clear that the pattern of stability was disrupted by the rain event (affecting both the wind speed and vertical temperature gradients) and the nocturnal dry periods tended to be more stable $\left(\mathrm{Ri}_{\mathrm{b}}>0.2\right)$ than the wet periods $\left(\mathrm{Ri}_{\mathrm{b}}<0.2\right)$ as shown in Fig. $13 \mathrm{c} 2$. The decreased stability in wet conditions is especially prevalent in the early evenings as discussed previously in relation to the vertical $\mathrm{CO}_{2}$ profiles (Sect. 3.2.3). Changes in VPD were closely related to changes in air temperature as reflected in how mean VPD changed with the precipitation state (Fig. 13b1 and b2). It is interesting that the pattern for nocturnal VPD (Fig. 13b2) was similar to that of stability (Fig. 13c2).

\section{Summary and conclusions}

Based on 14 years of 30 min measurements, the typical seasonal cycle and interannual variability of turbulent fluxes of sensible and latent heat and NEE from just-above a highelevation subalpine forest were presented. We used the snowpack ablation date to determine the start of the warm season and related this to the smoothed annual-flux time series. The warm season was further analyzed to determine how precipitation perturbed the ecosystem fluxes on a diel (i.e., hourly) time-scale. A simple, novel conditional sampling method based on whether the mean daily precipitation was greater than $3 \mathrm{~mm} \mathrm{day}^{-1}$ was used which essentially created a 4-day composite of a cold front passing by the tower (the dry days prior to the cold front, a day when the precipitation started, a day with precipitation on the preceding day, and the day following the precipitation event). Though the wet days comprised only $17 \%$ of the warm-season days, they accounted for around $85 \%$ of the total precipitation.

The results showed what might be expected for a coldfront passage in a mountainous location: an afternoon peak in precipitation, a $6{ }^{\circ} \mathrm{C}$ drop in air temperature, and a $50 \%$ increase in specific humidity. Changing from dry conditions to the wet, cool period of the composite front, we found the following changes during mid-day: net radiation decreased from around 585 to $275 \mathrm{~W} \mathrm{~m}^{-2}$ (over $50 \%$ ), sensible heat flux decreased from 280 to $85 \mathrm{~W} \mathrm{~m}^{-2}$ (around $70 \%$ ), latent heat flux was reduced from 170 to $125 \mathrm{~W} \mathrm{~m}^{-2}$ (around $25 \%$ ), and the magnitude of NEE was reduced from -7.8 to $-5.4 \mu \mathrm{mol} \mathrm{m}{ }^{-2} \mathrm{~s}^{-1}$ (around $30 \%$ ). Despite these dramatic changes to the individual component energy fluxes, the surface energy balance (SEB) closure during the daytime was between $90-110 \%$ throughout the 4-day composite frontal passage (Fig. 13a1). This level of SEB closure is consistent with previous research at the site (e.g., Turnipseed et al., 2002) and there was a slight dependence on the precipitation state. In our study, most of the storage terms were calculated based on biomass properties in the lower part of the canopy. Several recommendations of potential improvements with regard to the SEB are the following: (1) take into account the vertical variation of biomass properties, (2) use canopy and needle temperatures based on radiometric temperature measurements, (3) calculate storage terms using temperature lags in the soil and biomass (e.g., Lindroth et al., 2010), (4) improve our knowledge of soil properties (especially how they 
vary with depth), (5) examine the effect of flow distortion on the turbulent fluxes (e.g., Horst et al., 2015), and (6) explore calculating the sensible heat flux using a thermocouple rather than sonic temperature for warm-season conditions (e.g., Burns et al., 2012).

For a typical day following a rain event, net radiation and sensible heat flux both recovered to slightly below dryday values. Latent heat flux, however, increased from a dryday value of 170 to nearly $200 \mathrm{~W} \mathrm{~m}^{-2}$. Because LE also increased at night, we conclude that LE primarily increased due to evaporation of liquid water from within the soil. The enhanced LE due to evaporation lasted at least $18 \mathrm{~h}$, after which time it returned to a value similar to that of dry conditions (Fig. 9c). Another example of the effect of increased evaporation was the creation of a mid-day stable temperature layer within the forest sub-canopy (Fig. 4e). We conclude that the stable layer formed due to a combination of the vegetation being warmed by solar radiation and evaporative cooling near the ground. For NEE, we found that the subalpine forest at the US-NR1 site was most effective in assimilating $\mathrm{CO}_{2}$ on the day following a significant rain event. A closer look at the diel cycle reveals that increased NEE occurred during the afternoon of a day following rain (Fig. 9b).

Any effect of precipitation on nocturnal NEE and SEB closure was overshadowed by the influence of low winds and drainage flows. Precipitation also disrupted the typical dry-day diel pattern in several distinct ways: (1) it eliminated the dip of $\approx 1 \mathrm{~m} \mathrm{~s}^{-1}$ in above-canopy horizontal wind speed during the morning and evening transitions (Fig. 3d), (2) it generally led to lower overall levels of mechanical turbulence (Fig. 3e), and (3) it decreased the magnitude of subcanopy/above-canopy vertical air temperature differences (Fig. 4). These effects resulted in weakly stable conditions in the late evening during wet periods $\left(\mathrm{Ri}_{\mathrm{b}} \approx 0.1\right)$ compared to the more strongly stable dry periods $\left(\mathrm{Ri}_{\mathrm{b}} \approx 0.2\right)$. These stability differences contributed to smaller $\mathrm{CO}_{2}$ vertical differences (relative to above-canopy $\mathrm{CO}_{2}$ ) in the wet (less stable) conditions. After midnight, stability increased for both wet and dry conditions which created $\mathrm{CO}_{2}$ vertical differences that were similar in both wet and dry conditions. Despite the stronger stability after midnight there was also increased wind speed and mechanical turbulence (especially in dry conditions) which should result in increased vertical mixing. Further examination of these nighttime phenomena are beyond the scope of the current study but are recommended for future investigations.
By comparing cloudy and cloud-free days during dry periods we found that clouds shifted the diel maximum in sensible and latent heat fluxes from 12:00 MST on clear days to around 11:00 MST on cloudy days. Also, mid-day net radiation and sensible heat flux were enhanced by about $20 \%$ on clear days relative to cloudy days. In contrast, the timing of the peak in NEE (at around 10:00 MST) was unaffected by clouds and the forest was more efficient at assimilating $\mathrm{CO}_{2}$ on cloudy days than clear days (Fig. 12b).

Our study has provided an example of one way to look at the complex interconnections between variables that make modeling ecosystems so challenging. We have centered our study on precipitation, but these techniques could easily be adapted to focus on some over variable. Furthermore, this type of analysis could be used to evaluate models at the hourly time-scale (e.g., Matheny et al., 2014). We have shown that precipitation is intrinsically linked to changes in air temperature, pressure, and atmospheric humidity. Our focus was on the local near-ground and source effects on the scalars and fluxes relative to precipitation during the warm season. Three items that we did not fully consider in our analysis are the following: (1) there are undoubtedly sub-seasonal variations within the warm season that might reveal different responses to precipitation; (2) we did not examine the effect of the magnitude of precipitation events on our results; and (3) the atmospheric boundary layer, and specifically the boundary layer height and entrainment, will also have an impact on the near-surface scalar concentrations and fluxes (e.g., Culf et al., 1997; Freedman et al., 2001; van Heerwaarden et al., 2009; Pino et al., 2012; Pietersen et al., 2015). Characteristics such as boundary-layer height are linked to the larger-scale flows at the mountainous US-NR1 research site and will be considered in a future study. 


\section{Appendix A: Additional data details}

\section{A1 Additional measurements and calculations}

At US-NR1, the mean temperature and humidity profiles were measured with three mechanically aspirated, slow-response temperature-humidity sensors (Vaisala, model HMP35-D) installed at 2, 8, and $21.5 \mathrm{~m}$ a.g.l. The vertical temperature profile was enhanced by a set of 12 bare $0.254 \mathrm{~mm}$ diameter type-E chromel-constantan thermocouples distributed between the ground and $21.98 \mathrm{~m}$ a.g.l. In October 2005, a soil moisture sensor (Campbell Scientific, model CS616) and soil temperature sensor (Campbell Scientific, model CS107) were installed horizontally at a depth of $5 \mathrm{~cm}$ within $15 \mathrm{~m}$ of the US-NR1 tower. Prior to deployment, the CS107 thermistor was calibrated against a NISTstandard temperature sensor at the National Center for Atmospheric Research (NCAR) Integrated Surface Flux System (ISFS) calibration facility. These sensors were incorporated in the US-NR1 data set starting in January 2006. Prior to this, an average of five soil temperature sensors (REBS, model STP-1) and eight soil moisture sensors (Campbell Scientific, model CS615) were used to determine the soil properties. The CS615 sensors were inserted into the soil at a $45^{\circ}$ angle providing an average moisture content over the upper $15 \mathrm{~cm}$ of the soil. Soil heat flux $\left(G_{\text {plate }}\right)$ was measured with 4-5 soil heat flux plates (REBS, model HFT-1) dispersed near the tower at a depth of $8-10 \mathrm{~cm}$.

Additional information related to the diel cycle was provided by estimating the top-of-the-atmosphere incoming solar radiation $\left(Q_{\mathrm{SW}}^{\downarrow}\right)$ TOA. The sun position was calculated for the US-NR1 tower latitude and longitude with the SEAMAT Air-Sea toolbox (Woods Hole Oceanographic Institution, 2013) which uses algorithms based on the 1978 edition of the Almanac for Computers (Nautical Almanac Office, U. S. Naval Observatory).

Heat-pulse sap flow sensors were installed in the three dominant tree species (spruce, pine, and fir) near the US-NR1 tower during the summers of 2004, 2006 and 2007. Further details about the instrumentation and methods used are in Moore et al. (2008) and $\mathrm{Hu}$ et al. (2010b). In general, the pine and spruce trees make the largest contribution to transpiration and empirical relationships between transpiration and VPD from the summer of 2006 determined by Hu et al. (2010b) are shown in Fig. 11a2. For our study, we selected sensors for each summer from different pine and spruce trees that had similar year-to-year values of sap flow. To track relative changes in transpiration, we normalized the sap flow measurements using the maximum sap flow over the diel cycle in dDry conditions as shown for the pine trees in Fig. 9e. Here, we observed that the mid-day transpiration rate for pine trees on wDry days was about $20 \%$ lower than that of dDry days. For spruce trees, the mid-day transpiration rate on wDry days was very similar to that of dDry days (results not shown).
Leaf wetness was measured just below canopy-top with a horizontally oriented resistive-grid type wetness sensor (Campbell Scientific, model 237) between 1 July of 1999 to the present day. The output from the sensor has been normalized so that a value of zero corresponds to dry conditions while a value of one corresponds to completely wet conditions. Values between 0 and 1 correspond to "slightly wet" conditions.

Precipitation was measured on the US-NR1 tower at $11.5 \mathrm{~m}$ (canopy top) with a tipping bucket rain gauge (Campbell Scientific, Met One Model 385) starting in late summer of 1999. Two nearby precipitation-measurement sites were used to check the Met One data quality and for gapfilling. One station was part of the US Climate Reference Network (USCRN; Diamond et al., 2013; site: CO Boulder 14 W, Mountain Research Station, Hills Mill) located about $700 \mathrm{~m}$ northeast of US-NR1. These measurements started in 2004 using a Geonor T-200B precipitation gauge with a small double fence intercomparison reference (SDFIR) type of wind shield around the gauge. The second site is operated by the Niwot Ridge Long Term Ecological Research (LTER) Mountain Climate Program where both a Geonor T200B gauge (unshielded) and, for the longer-term record dating back to 1953, a Belfort precipitation gauge strip-chart recorder for daily precipitation were used (e.g., Greenland, 1989; Williams et al., 1996). The LTER sensors were located about $550 \mathrm{~m}$ northeast of the US-NR1 tower. Though in winter the unshielded Met One gauge grossly underestimated total precipitation due to snow blowing by the tipping bucket gauge (e.g., Rasmussen et al., 2012), the warm-season cumulative precipitation between the USCRN and Met One gauges were typically within about $20 \mathrm{~cm}$ of each other (with a typical mean value of $250 \mathrm{~cm}$ ). However, starting in summer of 2011, the Met One gauge started showing much greater precipitation amounts which we suspect was due to the "points" which hold the tipping bucket becoming worn and loose (in winter of 2013, the sensor failed completely). Therefore, the precipitation data used for the summers of 2011 and 2012 were exclusively from the USCRN sensor. Because the USNR1 Met One sensor was not installed until late summer of 1999, the LTER Geonor data were used for the 1999 warm season. However, prior to year 2000 , only daily precipitation was measured by LTER so hourly precipitation data were not available for 1999. This allows for the determination of a wet day in summer 1999, but not examination of the diel cycle of precipitation.

Based on 8 years of precipitation data from a nearby US Climate Reference Network (USCRN) site, April had the most precipitation (with a mean of around $120 \mathrm{~mm}$, almost all falling as snow) followed by July with $90 \mathrm{~mm}$ of precipitation (Fig. S1a in the Supplement). April and July were also the months with the largest variability between years and the variations between years were about $50 \%$ of the mean value (Fig. S1b). These trends generally agree with the long-term precipitation measurements from the LTER C-1 (1953-2012) 
station where the effect of undercatch by the LTER gauge is noticeable during the winter months.

Carbon dioxide dry mole fraction was measured on the US-NR1 tower with a tunable diode laser (TDL) absorption spectrometer (Campbell Scientific, model TGA100A) as described by Bowling et al. (2005); Schaeffer et al. (2008b). Measurements were made in summer of 2003 and continuously from fall of 2005 to the present. For our study, nine TDL inlets between 0.1 and $21.5 \mathrm{~m}$ a.g.l. were used to evaluate the $\mathrm{CO}_{2}$ profile. The precision of TDL $\mathrm{CO}_{2}$ mole fraction is estimated to be about $0.2 \mu \mathrm{mol} \mathrm{mol}^{-1}$ (Schaeffer et al., 2008b). The TDL $\mathrm{CO}_{2}$ data were downloaded on 7 January 2013 from http://biologylabs.utah.edu/bowling/. For calculating the storage term in NEE, an independent $\mathrm{CO}_{2}$-profile system with a closed-path IRGA (LI-COR, model LI-6251) was used as described in Monson et al. (2002).

\section{A2 Soil heat flux and storage terms in the surface energy balance}

The storage terms in the surface energy balance are

$S_{\mathrm{tot}}=S_{H}+S_{\mathrm{LE}}+S_{\mathrm{b}}+S_{\mathrm{n}}+J_{A}$,

where $S_{H}$ and $S_{\mathrm{LE}}$ are the sensible and latent heat energy stored in the air space between the ground and fluxmeasurement level, $S_{\mathrm{b}}$ is heat stored in the tree boles, and $S_{\mathrm{n}}$ is heat stored in the tree needles. $J_{A}$ is the energy consumed by photosynthesis which was estimated by Turnipseed et al. (2002) to be small, so we have neglected it. The tree bole temperatures were measured with thermocouples in each tree species (seven pine trees, three fir trees, and two spruce trees) at a nominal depth of $3 \mathrm{~cm}$ into the bole and at three vertical heights (near the ground, 0.5, and $1.5 \mathrm{~m}$ ). The $1.5 \mathrm{~m}$ sensors were used to calculate the $S_{\mathrm{b}}$ term (to avoid snowpack effects in winter). Bole temperatures from the summers of 2011 and 2012 had a multiplexer problem, so these years were excluded from the storage term calculation. The needle temperature was estimated using the $8 \mathrm{~m}$ air temperature as a proxy for the true needle temperature. The storage terms in Eq. (A1) were all calculated as described by Turnipseed et al. (2002), and interested readers should look there for additional details. The individual storage terms are shown over the diel cycle for each precipitation states in Fig. S2b1-b4. $S_{\text {tot }}$ was at a maximum during dry conditions with a value near $100 \mathrm{~W} \mathrm{~m}^{-2}$ which corresponds to about $15 \%$ of $R_{\text {net }}$ (Fig. S2a1-a4).

The heat flux at the soil surface $(G)$ was calculated from the average soil heat flux from the $\approx 10 \mathrm{~cm}$ deep heat-flux plates combined with the heat storage in the soil above the heat-flux plates $S_{\text {soil }}$ (e.g., Oncley et al., 2007),

$G=G_{\text {plate }}+S_{\text {soil }}$.

The soil storage term was calculated with

$S_{\text {soil }}=C_{\text {soil }} z_{p} \frac{d \bar{T}_{\text {soil }}}{d t}$, where $C_{\text {soil }}$ is the volumetric heat capacity of the soil $\left[\mathrm{J} \mathrm{m}^{-3} \mathrm{~K}^{-1}\right], z_{p}$ is the depth of the heat-flux plates, and $\bar{T}_{\text {soil }}$ is the average temperature of the soil layer above the heatflux plates. For $\bar{T}_{\text {soil }}$, the CS107 sensor at a depth of $5 \mathrm{~cm}$ was used starting in summer of 2006. If the heat capacity of air within the soil matrix is neglected, then $C_{\text {soil }}$ depends on the amount of water within the soil and can be calculated from

$C_{\text {soil }}=\rho_{\text {water }} c_{\text {water }} \mathrm{VWC}+\rho_{\text {soil.dry }} c_{\text {soil.dry }}$,

where the density of dry soil $\rho_{\text {soil.dry }}$ was assumed to be $1700 \mathrm{~kg} \mathrm{~m}^{-3}$ with a specific heat capacity $c_{\text {soil.dry }}$ of $900 \mathrm{~J} \mathrm{~kg}^{-1} \mathrm{~K}^{-1}$. For water, the values of $\rho_{\text {water }}$ and $c_{\text {water }}$ used were $998 \mathrm{~kg} \mathrm{~m}^{-3}$ and $4182 \mathrm{~J} \mathrm{~kg}^{-1} \mathrm{~K}^{-1}$, respectively. The volumetric water content VWC of the soil ranged between less than $0.1 \mathrm{~m}^{3} \mathrm{~m}^{-3}$ for dry soil to around $0.4 \mathrm{~m}^{3} \mathrm{~m}^{-3}$ for saturated soil. At mid-day, the soil storage term was found to be about twice as large as the measured soil heat flux (Fig. S2c1-c4).

\section{A3 Updates to US-NR1 AmeriFlux data}

The version of the US-NR1 AmeriFlux data used in our study (ver.2011.04.20 for years 1998-2010, ver.2012.03.12 for 2011, and ver.2013.02.28 for 2012) includes a correction for an error in the closed-path IRGA $\mathrm{CO}_{2}$ flux calculation where a water-vapor correction was applied twice: first, as a sample-by-sample dilution correction and second by including the Webb-Pearman-Leuning (WPL) term in the $\mathrm{CO}_{2}$ flux (e.g., Ibrom et al., 2007). After the error was discovered in Fall of 2010, the $\mathrm{CO}_{2}$ flux (and NEE) for all years were recalculated from the raw $10 \mathrm{~Hz}$ data with only the dilution correction applied and the updated/fixed data set was released on 20 April 2011 (http://urquell.colorado.edu/data_ameriflux/). Though the point-by-point difference between the correct and incorrect $30 \mathrm{~min}$ NEE values appears small, when accumulated over a year, the correctly calculated NEE approximately doubled the annual uptake of $\mathrm{CO}_{2}$ by the US-NR1 forest. The accumulation of a systematic measurement error over time is a well-known issue in the flux community (Moncrieff et al., 1996). Several side-by-side instrument comparisons by the AmeriFlux QA/QC team (e.g., Schmidt et al., 2012; Chan et al., 2014) have found the US-NR1 measurements to be of high quality (and also helped to assess the calculation error of the $\mathrm{CO}_{2}$ flux).

\section{A4 Time series of measured fluxes}

During the discussion portion of the review it was suggested that a time series of the fluxes be provided. Bin averaging can sometimes produce misleading results, so we agreed with this suggestion. A time series of the measured fluxes is shown in Fig. S3. This period includes a large rain event between days 188 and 191. On the day following this rainy period, there was enhanced latent heat flux (Fig. S3c), which 
is a characteristic similar to what we found using the binaveraged data.

\section{A5 Comparison of gap-filled and non-gap-filled fluxes}

At the request of associate editor Georg Wohlfahrt, we have included a comparison of the diel cycle for gap-filled and non-gap-filled fluxes in Fig. S4. Effects of gap-filling on the mean composite diel cycle are primarily small; however, differences can be observed during wWet conditions where the average number of gap-filled periods is largest, at around $38 \%$ (i.e., Table 2). 


\section{The Supplement related to this article is available online at doi:10.5194/bg-12-7349-2015-supplement.}

Acknowledgements. We thank the Niwot Ridge LTER team (Katharine Suding, Mark Williams, Jennifer Morse, and many others) for maintaining the LTER instruments and making these data available. Dave Bowling, Don Lenschow, Arnold Moene, and Jielun Sun provided helpful discussions. Two anonymous reviewers made insightful comments that improved the manuscript. We also appreciate site visits and evaluation of the US-NR1 measurements by the AmeriFlux QA/QC team (Sébastien Biraud and Stephen Chan in 2013; and Christoph Thomas in 2006). Carbon dioxide profile measurements were supported by grants to Dave Bowling from the US Department of Energy (DOE), Office of Science, Office of Biological and Environmental Research, Terrestrial Ecosystem Science Program under Award Numbers DE-SC0005236 and DE-SC001625. We also acknowledge the US Climate Reference Network (USCRN) for collecting high-quality data and creating a database that is accessible and simple. The US-NR1 AmeriFlux site is currently supported by the US DOE, Office of Science through the AmeriFlux Management Project (AMP) at Lawrence Berkeley National Laboratory under Award Number 7094866. The National Center for Atmospheric Research (NCAR) is sponsored by NSF.

Edited by: G. Wohlfahrt

\section{References}

Acevedo, O. C., Moraes, O. L. L., Degrazia, G. A., Fitzjarrald, D. R., Manzi, A. O., and Campos, J. G.: Is friction velocity the most appropriate scale for correcting nocturnal carbon dioxide fluxes?, Agr. Forest Meteorol., 149, 1-10, 2009.

Alekseychik, P., Mammarella, I., Launiainen, S., Rannik, Ü., and Vesala, T.: Evolution of the nocturnal decoupled layer in a pine forest canopy, Agr. Forest Meteorol., 174-175, 15-27, 2013.

Alexander, R. R.: Ecology, Silviculture, and Management of the Engelmann Spruce - Subalpine Fir Type in the Central and Southern Rocky Mountains, USDA Forest Service, Agriculture Handbook No. 659, 144 pp., 1987.

Aubinet, M.: Eddy covariance $\mathrm{CO}_{2}$ flux measurements in nocturnal conditions: An analysis of the problem, Ecol. Appl., 18, 13681378, 2008.

Aubinet, M., Grelle, A., Ibrom, A., Rannik, U., Moncrieff, J., Foken, T., Kowalski, A. S., Martin, P. H., Berbigier, P., Bernhofer, C., Clement, R., Elbers, J., Granier, A., Grunwald, T., Morgenstern, K., Pilegaard, K., Rebmann, C., Snijders, W., Valentini, R., and Vesala, T.: Estimates of the annual net carbon and water exchange of forests: The EUROFLUX methodology, Adv. Ecol. Res., 30, 113-175, 2000.

Aubinet, M., Berbigier, P., Bernhofer, C. H., Cescatti, A., Feigenwinter, C., Granier, A., Grunwald, T. H., Havrankova, K., Heinesch, B., Longdoz, B., Marcolla, B., Montagnani, L., and Sedlak, P.: Comparing $\mathrm{CO}_{2}$ storage and advection conditions at night at different CARBOEUROFLUX sites, Bound.-Lay. Meteorol., 116, 63-94, 2005.
Aubinet, M., Vesala, T., and Papale, D.: Eddy Covariance: A Practical Guide to Measurement and Data Analysis, Springer Atmospheric Sciences, Dordrecht, The Netherlands, 438 pp., 2012.

Austin, A. T., Yahdjian, L., Stark, J. M., Belnap, J., Porporato, A., Norton, U., Ravetta, D. A., and Schaeffer, S. M.: Water pulses and biogeochemical cycles in arid and semiarid ecosystems, Oecologia, 141, 221-235, 2004.

Baldocchi, D., Finnigan, J., Wilson, K., Paw U, K. T., and Falge, E.: On measuring net ecosystem carbon exchange over tall vegetation on complex terrain, Bound.-Lay. Meteorol., 96, 257-291, 2000.

Baldocchi, D. D.: Assessing the eddy covariance technique for evaluating carbon dioxide exchange rates of ecosystems: past, present and future, Glob. Change Biol., 9, 479-492, 2003.

Baldocchi, D. D. and Meyers, T. P.: Trace gas-exchange above the floor of a deciduous forest 1. Evaporation and $\mathrm{CO}_{2}$ efflux, J. Geophys. Res., 96, 7271-7285, 1991.

Beerling, D. J.: Gas valves, forests and global change: a commentary on Jarvis (1976) 'The interpretation of the variations in leaf water potential and stomatal conductance found in canopies in the field', Philos. T. Roy. Soc. B, 370, 20140311, doi:10.1098/rstb.2014.0311, 2015.

Berkelhammer, M., Hu, J., Bailey, A., Noone, D. C., Still, C. J., Barnard, H., Gochis, D., Hsiao, G. S., Rahn, T., and Turnipseed, A.: The nocturnal water cycle in an open-canopy forest, J. Geophys. Res., 118, 1-18, 2013.

Betts, A. K. and Ball, J. H.: The FIFE surface diurnal cycle climate, J. Geophys. Res., 100, 25679-25693, 1995.

Blanken, P. D., Black, T. A., Yang, P. C., Neumann, H. H., Nesic, Z., Staebler, R., den Hartog, G., Novak, M. D., and Lee, X.: Energy balance and canopy conductance of a boreal aspen forest: Partitioning overstory and understory components, J. Geophys. Res., 102, 28915-28927, 1997.

Blanken, P. D., Black, T. A., Neumann, H. H., den Hartog, G., Yang, P. C., Nesic, Z., and Lee, X.: The seasonal water and energy exchange above and within a boreal aspen forest, J. Hydrol., 245, 118-136, 2001.

Bonan, G.: Ecological Climatology: Concepts and Applications, Cambridge University Press, Cambridge, UK, 2nd edn., 550 pp., 2008.

Bowling, D. R., Burns, S. P., Conway, T. J., Monson, R. K., and White, J. W. C.: Extensive observations of $\mathrm{CO}_{2}$ carbon isotope content in and above a high-elevation subalpine forest, Global Biogeochem. Cy., 19, GB3023, doi:10.1029/2004GB002394, 2005.

Bowling, D. R., Miller, J. B., Rhodes, M. E., Burns, S. P., Monson, R. K., and Baer, D.: Soil, plant, and transport influences on methane in a subalpine forest under high ultraviolet irradiance, Biogeosciences, 6, 1311-1324, doi:10.5194/bg-6-13112009, 2009.

Bowling, D. R., Grote, E. E., and Belnap, J.: Rain pulse response of soil $\mathrm{CO}_{2}$ exchange by biological soil crusts and grasslands of the semiarid Colorado Plateau, United States, J. Geophys. Res., 116, G03028, doi:10.1029/2011JG001643, 2011.

Bowling, D. R., Ballantyne, A. P., Miller, J. B., Burns, S. P., Conway, T. J., Menzer, O., Stephens, B. B., and Vaughn, B. H.: Ecological processes dominate the ${ }^{13} \mathrm{C}$ land disequilibrium in a Rocky Mountain subalpine forest, Global Biogeochem. Cy., 28, 352-370, doi:10.1002/2013GB004686, 2014. 
Brazel, A. J. and Brazel, S. W.: Summer diurnal wind patterns at 3,000 m surface level, Front Range, Colorado, USA, Phys. Geog., 4, 53-61, 1983.

Brutsaert, W.: Evaporation into the Atmosphere, Kluwer Academic Publishers, Dordrecht, The Netherlands, 299 pp., 1982.

Burns, S. P., Sun, J., Lenschow, D. H., Oncley, S. P., Stephens, B. B., Yi, C., Anderson, D. E., Hu, J., and Monson, R. K.: Atmospheric stability effects on wind fields and scalar mixing within and just above a subalpine forest in sloping terrain, Bound.-Lay. Meteorol., 138, 231-262, doi:10.1007/s10546-010-9560-6, 2011.

Burns, S. P., Horst, T. W., Jacobsen, L., Blanken, P. D., and Monson, R. K.: Using sonic anemometer temperature to measure sensible heat flux in strong winds, Atmos. Meas. Tech., 5, 2095-2111, doi:10.5194/amt-5-2095-2012, 2012.

Burns, S. P., Molotch, N. P., Williams, M. W., Knowles, J. F., Seok, B., Monson, R. K., Turnipseed, A. A., and Blanken, P. D.: Snow temperature changes within a seasonal snowpack and their relationship to turbulent fluxes of sensible and latent heat, J. Hydrometeorol., 15, 117-142, doi:10.1175/JHM-D-13-026.1, 2013.

Burns, S. P., Blanken, P. D., Turnipseed, A. A., and Monson, R. K.: The effect of warm-season precipitation on the diel cycle of the surface energy balance and carbon dioxide at a Colorado subalpine forest site, Biogeosciences Discuss., 12, 8939-9004, doi:10.5194/bgd-12-8939-2015, 2015.

Chan, S., Biraud, S., and Billesbach, D.: AmeriFlux QA/QC Report on US-NR1/PECS Comparison between 29 July and 3 August 2013, Tech. rep., Earth Sciences Division, Lawerence Berkeley National Laboratory, Berkeley, CA, 48 pp., 2014.

Culf, A. D., Fisch, G., Malhi, Y., and Nobre, C. A.: The influence of the atmospheric boundary layer on carbon dioxide concentrations over a tropical forest, Agr. Forest Meteorol., 85, 149-158, 1997.

Dalton, J.: Experimental essays on the constitution of mixed gases; on the force of steam or vapour from water and other liquids at different temperatures, both in a Torricellian vacuum and in air; on evaporation and on the expansion of gas by heat, Mem. Manchester Lit. and Phil. Soc., 5, 535-602, 1802.

Diamond, H. J., Karl, T. R., Palecki, M. A., Baker, C. B., Bell, J. E., Leeper, R. D., Easterling, D. R., Lawrimore, J. H., Meyers, T. P., Helfert, M. R., Goodge, G., and Thorne, P. W.: US Climate Reference Network after one decade of operations: status and assessment, B. Am. Meteorol. Soc., 94, 485-498, 2013.

Edburg, S. L., Stock, D., Lamb, B. K., and Patton, E. G.: The effect of the vertical source distribution on scalar statistics within and above a forest canopy, Bound.-Lay. Meteorol., 142, 365-382, 2012.

Egger, J. and Hoinka, K. P.: Fronts and Orography, Meteorol. Atmos. Phys., 48, 3-36, 1992.

Finnigan, J.: An introduction to flux measurements in difficult conditions, Ecol. Appl., 18, 1340-1350, 2008.

Freedman, J. M., Fitzjarrald, D. R., Moore, K. E., and Sakai, R. K.: Boundary layer clouds and vegetation-atmosphere feedbacks, J. Climate, 14, 180-197, 2001.

Froelich, N. J., Grimmond, C. S. B., and Schmid, H. P.: Nocturnal cooling below a forest canopy: Model and evaluation, Agr. Forest Meteorol., 151, 957-968, 2011.

Geiger, R., Aron, R. H., and Todhunter, P.: The Climate Near the Ground, Rowman \& Littlefield, Oxford, sixth edn., 584 pp., 2003.
Goulden, M. L., Munger, J. W., Fan, S. M., Daube, B. C., and Wofsy, S. C.: Measurements of carbon sequestration by long-term eddy covariance: Methods and a critical evaluation of accuracy, Glob. Change Biol., 2, 169-182, 1996.

Greenland, D.: The climate of Niwot Ridge, Front Range, Colorado, USA, Arctic Alpine Res., 21, 380-391, 1989.

Greenland, D.: Mountain climates, in: Encyclopedia of World Climatology, edited by Oliver, J. E., Encyclopedia of Earth Sciences Series, pp. 517-523, Springer, Dordrecht, the Netherlands, doi:10.1007/1-4020-3266-8_145, 2005.

Grelle, A., Lundberg, A., Lindroth, A., Moren, A.-S., and Cienciala, E.: Evaporation components of a boreal forest: variations during the growing season, J. Hydrol., 197, 70-87, 1997.

Grimmond, C. S. B., Isard, S. A., and Belding, M. J.: Development and evaluation of continuously weighing mini-lysimeters, Agr Forest Meteorol., 62, 205-218, 1992.

Gu, L. H., Fuentes, J. D., Shugart, H. H., Staebler, R. M., and Black, T. A.: Responses of net ecosystem exchanges of carbon dioxide to changes in cloudiness: Results from two North American deciduous forests, J. Geophys. Res., 104, 31421-31434, 1999.

Gu, L. H., Baldocchi, D., Verma, S. B., Black, T. A., Vesala, T., Falge, E. M., and Dowty, P. R.: Advantages of diffuse radiation for terrestrial ecosystem productivity, J. Geophys. Res., 107, 4050, doi:10.1029/2001JD001242, 2002.

Hirano, T., Kim, H., and Tanaka, Y.: Long-term half-hourly measurement of soil $\mathrm{CO}_{2}$ concentration and soil respiration in a temperate deciduous forest, J. Geophys. Res., 108, 4631, doi:10.1029/2003JD003766, 2003.

Hogg, E. H., Black, T. A., den Hartog, G., Neumann, H. H., Zimmermann, R., Hurdle, P. A., Blanken, P. D., Nesic, Z., Yang, P. C., Staebler, R. M., McDonald, K. C., and Oren, R.: A comparison of sap flow and eddy fluxes of water vapor from a boreal deciduous forest, J. Geophys. Res., 102, 28929-28937, 1997.

Horst, T. W., Semmer, S. R., and Maclean, G.: Correction of a nonorthogonal, three-component sonic anemometer for flow distortion by transducer shadowing, Bound.-Lay. Meteorol., 155, 371395, doi:10.1007/s10546-015-0010-3, 2015.

Hu, J., Moore, D. J. P., Burns, S. P., and Monson, R. K.: Longer growing seasons lead to less carbon sequestration by a subalpine forest, Glob. Change Biol., 16, 771-783, doi:10.1111/j.13652486.2009.01967.x, 2010a.

Hu, J., Moore, D. J. P., Riveros-Iregui, D. A., Burns, S. P., and Monson, R. K.: Modeling whole-tree carbon assimilation rate using observed transpiration rates and needle sugar carbon isotope ratios, New Phytol., 185, 1000-1015, doi:10.1111/j.14698137.2009.03154.x, 2010b.

Huxman, T. E., Turnipseed, A. A., Sparks, J. P., Harley, P. C., and Monson, R. K.: Temperature as a control over ecosystem $\mathrm{CO}_{2}$ fluxes in a high-elevation, subalpine forest, Oecologia, 134, 537546, 2003.

Huxman, T. E., Snyder, K. A., Tissue, D., Leffler, A. J., Ogle, K., Pockman, W. T., Sandquist, D. R., Potts, D. L., and Schwinning, S.: Precipitation pulses and carbon fluxes in semiarid and arid ecosystems, Oecologia, 141, 254-268, 2004.

Ibrom, A., Dellwik, E., Larsen, S. E., and Pilegaard, K.: On the use of the Webb-Pearman-Leuning theory for closed-path eddy correlation measurements, Tellus B, 59, 937-946, 2007.

Inglima, I., Alberti, G., Bertolini, T., Vaccari, F. P., Gioli, B., Miglietta, F., Cotrufo, M. F., and Peressotti, A.: Precipitation pulses 
enhance respiration of Mediterranean ecosystems: the balance between organic and inorganic components of increased soil $\mathrm{CO}_{2}$ efflux, Glob. Change Biol., 15, 1289-1301, 2009.

Irvine, J. and Law, B. E.: Contrasting soil respiration in young and old-growth ponderosa pine forests, Glob. Change Biol., 8, 11831194, 2002.

Ivans, S., Hipps, L., Leffler, A. J., and Ivans, C. Y.: Response of water vapor and $\mathrm{CO}_{2}$ fluxes in semiarid lands to seasonal and intermittent precipitation pulses, J. Hydrometeorol., 7, 995-1010, 2006.

Jarvis, P., Rey, A., Petsikos, C., Wingate, L., Rayment, M., Pereira, J., Banza, J., David, J., Miglietta, F., Borghetti, M., Manca, G., and Valentini, R.: Drying and wetting of Mediterranean soils stimulates decomposition and carbon dioxide emission: The "Birch effect", Tree Physiol., 27, 929-940, 2007.

Jarvis, P. G. and McNaughton, K. G.: Stomatal control of transpiration: Scaling up from leaf to region, Adv. Ecol. Res., 15, 1-49, 1986.

Jasechko, S., Sharp, Z. D., Gibson, J. J., Birks, S. J., Yi, Y., and Fawcett, P. J.: Terrestrial water fluxes dominated by transpiration, Nature, 496, 347-351, 2013.

Jenerette, G. D., Scott, R. L., and Huxman, T. E.: Whole ecosystem metabolic pulses following precipitation events, Funct. Ecol., 22, 924-930, 2008.

Katul, G. G., Oren, R., Manzoni, S., Higgins, C., and Parlange, M. B.: Evapotranspiration: a process driving mass transport and energy exchange in the soil-plant-atmosphere-climate system, Rev. Geophys., 50, RG3002, doi:10.1029/2011RG000366, 2012.

Kim, D., Oren, R., Oishi, A. C., Hsieh, C. I., Phillips, N., Novick, K. A., and Stoy, P. C.: Sensitivity of stand transpiration to wind velocity in a mixed broadleaved deciduous forest, Agr. Forest Meteorol., 187, 62-71, 2014.

Knowles, J. F., Burns, S. P., Blanken, P. D., and Monson, R. K.: Fluxes of energy, water, and carbon dioxide from mountain ecosystems at Niwot Ridge, Colorado, Plant Ecol. Divers., doi:10.1080/17550874.2014.904950, 2014.

Kottek, M., Grieser, J., Beck, C., Rudolf, B., and Rubel, F.: World Map of the Köppen-Geiger climate classification updated, Meteorol. Z., 15, 259-263, doi:10.1127/0941-2948/2006/0130, 2006.

Lasslop, G., Reichstein, M., Papale, D., Richardson, A. D., Arneth, A., Barr, A., Stoy, P., and Wohlfahrt, G.: Separation of net ecosystem exchange into assimilation and respiration using a light response curve approach: critical issues and global evaluation, Glob. Change Biol., 16, 187-208, 2010.

Law, B. E., Williams, M., Anthoni, P. M., Baldocchi, D. D., and Unsworth, M. H.: Measuring and modelling seasonal variation of carbon dioxide and water vapour exchange of a Pinus ponderosa forest subject to soil water deficit, Glob. Change Biol., 6, 613630, 2000.

Law, B. E., Falge, E., Gu, L., Baldocchi, D. D., Bakwin, P., Berbigier, P., Davis, K., Dolman, A. J., Falk, M., Fuentes, J. D., Goldstein, A., Granier, A., Grelle, A., Hollinger, D., Janssens, I. A., Jarvis, P., Jensen, N. O., Katul, G., Mahli, Y., Matteucci, G., Meyers, T., Monson, R., Munger, W., Oechel, W., Olson, R., Pilegaard, K., Paw, K. T., Thorgeirsson, H., Valentini, R., Verma, S., Vesala, T., Wilson, K., and Wofsy, S.: Environmental controls over carbon dioxide and water vapor exchange of terrestrial vegetation, Agr. Forest Meteorol., 113, 97-120, 2002.
Lawrence, D. M., Thornton, P. E., Oleson, K. W., and Bonan, G. B.: The partitioning of evapotranspiration into transpiration, soil evaporation, and canopy evaporation in a GCM: Impacts on land-atmosphere interaction, J. Hydrometeorol., 8, 862-880, 2007.

Lee, T. R., De Wekker, S. F. J., Andrews, A. E., Kofler, J., and Williams, J.: Carbon dioxide variability during cold front passages and fair weather days at a forested mountaintop site, Atmos. Environ., 46, 405-416, 2012.

Lee, X., Wu, H. J., Sigler, J., Oishi, C., and Siccama, T.: Rapid and transient response of soil respiration to rain, Glob. Change Biol., 10, 1017-1026, 2004.

Leuning, R., van Gorsel, E., Massman, W. J., and Isaac, P. R.: Reflections on the surface energy imbalance problem, Agr. Forest Meteorol., 156, 65-74, doi:10.1016/j.agrformet.2011.12.002, 2012.

Lindroth, A.: Seasonal and diurnal-variation of energy budget components in coniferous forests, J. Hydrol., 82, 1-15, 1985.

Lindroth, A., Mölder, M., and Lagergren, F.: Heat storage in forest biomass improves energy balance closure, Biogeosciences, 7 , 301-313, doi:10.5194/bg-7-301-2010, 2010.

Lindzen, R. S. and Chapman, S.: Atmospheric tides, Space Sci. Rev., 10, 3-188, 1969.

Lothon, M., Lohou, F., Pino, D., Couvreux, F., Pardyjak, E. R., Reuder, J., Vilà-Guerau de Arellano, J., Durand, P, Hartogensis, O., Legain, D., Augustin, P., Gioli, B., Lenschow, D. H., Faloona, I., Yagüe, C., Alexander, D. C., Angevine, W. M., Bargain, E, Barrié, J., Bazile, E., Bezombes, Y., Blay-Carreras, E., van de Boer, A., Boichard, J. L., Bourdon, A., Butet, A., Campistron, B., de Coster, O., Cuxart, J., Dabas, A., Darbieu, C., Deboudt, K., Delbarre, H., Derrien, S., Flament, P., Fourmentin, M., Garai, A., Gibert, F., Graf, A., Groebner, J., Guichard, F., Jiménez, M. A., Jonassen, M., van den Kroonenberg, A., Magliulo, V., Martin, S., Martinez, D., Mastrorillo, L., Moene, A. F., Molinos, F., Moulin, E., Pietersen, H. P., Piguet, B., Pique, E., RománCascón, C., Rufin-Soler, C., Saïd, F., Sastre-Marugán, M., Seity, Y., Steeneveld, G. J., Toscano, P., Traullé, O., Tzanos, D., Wacker, S., Wildmann, N., and Zaldei, A.: The BLLAST field experiment: Boundary-Layer Late Afternoon and Sunset Turbulence, Atmos. Chem. Phys., 14, 10931-10960, doi:10.5194/acp14-10931-2014, 2014.

Mahrt, L.: Stratified atmospheric boundary layers, Bound.-Lay. Meteorol., 90, 375-396, 1999.

Malhi, Y., Pegoraro, E., Nobre, A. D., Pereira, M. G. P., Grace, J., Culf, A. D., and Clement, R.: Energy and water dynamics of a central Amazonian rain forest, J. Geophys. Res., 107, 8061, doi:10.1029/2001JD000623, 2002.

Marr, J. W.: Ecosystems on the east slope of the Front Range in Colorado, Series in Biology, No. 8, University of Colorado Press, Boulder, Colorado, 144 pp., 1961.

Matheny, A. M., Bohrer, G., Stoy, P. C., Baker, I. T., Black, A. T., Desai, A. R., Dietze, M. C., Gough, C. M., Ivanov, V. Y., Jassal, R. S., Novick, K. A., Schafer, K. V. R., and Verbeeck, H.: Characterizing the diurnal patterns of errors in the prediction of evapotranspiration by several land-surface models: An NACP analysis, J. Geophys. Res., 119, 1458-1473, 2014.

Max Planck Institute for Biogeochemistry: Eddy covariance gapfilling and flux-partitioning tool, http://www.bgc-jena.mpg.de/ 126MDIwork/eddyproc/ (last access: June 2015), 2013. 
McNaughton, K. G. and Jarvis, P. G.: Effects of spatial scale on stomatal control of transpiration, Agr. Forest Meteorol., 54, 279302, 1991

Miles, N. L., Richardson, S. J., Davis, K. J., Lauvaux, T., Andrews, A. E., West, T. O., Bandaru, V., and Crosson, E. R.: Large amplitude spatial and temporal gradients in atmospheric boundary layer $\mathrm{CO}_{2}$ mole fractions detected with a tower-based network in the U.S. upper Midwest, J. Geophys. Res., 117, G01019, doi:10.1029/2011JG001781, 2012.

Misson, L., Gershenson, A., Tang, J. W., McKay, M., Cheng, W. X., and Goldstein, A.: Influences of canopy photosynthesis and summer rain pulses on root dynamics and soil respiration in a young ponderosa pine forest, Tree Physiol., 26, 833-844, 2006.

Misson, L., Baldocchi, D. D., Black, T. A., Blanken, P. D., Brunet, Y., Yuste, J. C., Dorsey, J. R., Falk, M., Granier, A., Irvine, M. R., Jarosz, N., Lamaud, E., Launiainen, S., Law, B. E., Longdoz, B., Loustau, D., Mckay, M., Paw, K. T., Vesala, T., Vickers, D., Wilson, K. B., and Goldstein, A. H.: Partitioning forest carbon fluxes with overstory and understory eddy-covariance measurements: A synthesis based on FLUXNET data, Agr. Forest Meteorol., 144, 14-31, 2007.

Moene, A. F. and Van Dam, J. C.: Transport in the AtmosphereVegetation-Soil Continuum, Cambridge University Press, New York, 458 pp., 2014.

Moncrieff, J. B., Malhi, Y., and Leuning, R.: The propagation of errors in long-term measurements of land-atmosphere fluxes of carbon and water, Glob. Change Biol., 2, 231-240, 1996.

Monson, R. K., Turnipseed, A. A., Sparks, J. P., Harley, P. C., ScottDenton, L. E., Sparks, K., and Huxman, T. E.: Carbon sequestration in a high-elevation, subalpine forest, Glob. Change Biol., 8, 459-478, 2002.

Monson, R. K., Sparks, J. P., Rosenstiel, T. N., Scott-Denton, L. E., Huxman, T. E., Harley, P. C., Turnipseed, A. A., Burns, S. P., Backlund, B., and Hu, J.: Climatic influences on net ecosystem $\mathrm{CO}_{2}$ exchange during the transition from wintertime carbon source to springtime carbon sink in a high-elevation, subalpine forest, Oecologia, 146, 130-147, 2005.

Monson, R. K., Prater, M. R., Hu, J., Burns, S. P., Sparks, J. P., Sparks, K. L., and Scott-Denton, L. E.: Tree species effects on ecosystem water-use efficiency in a high-elevation, subalpine forest, Oecologia, 162, 491-504, doi:10.1007/s00442-009-1465z, 2010.

Monteith, J. L.: Evaporation and environment, in: The State and Movement of Water in Living Organisms, edited by: Fogg, G. E., 205-234, Academic Press, New York, 1965.

Monteith, J. L.: A reinterpretation of stomatal responses to humidity, Plant Cell Environ., 18, 357-364, 1995.

Moore, D. J. P., Hu, J., Sacks, W. J., Schimel, D. S., and Monson, R. K.: Estimating transpiration and the sensitivity of carbon uptake to water availability in a subalpine forest using a simple ecosystem process model informed by measured net $\mathrm{CO}_{2}$ and $\mathrm{H}_{2} \mathrm{O}$ fluxes, Agr. Forest Meteorol., 148, 1467-1477, 2008.

Munson, S. M., Benton, T. J., Lauenroth, W. K., and Burke, I. C.: Soil carbon flux following pulse precipitation events in the shortgrass steppe, Ecol. Res., 25, 205-211, 2010.

Novick, K. A., Stoy, P. C., Katul, G. G., Ellsworth, D. S., Siqueira, M. B. S., Juang, J., and Oren, R.: Carbon dioxide and water vapor exchange in a warm temperate grassland, Oecologia, 138, 259$274,2004$.
Novick, K. A., Oren, R., Stoy, P. C., Siqueira, M. B. S., and Katul, G. G.: Nocturnal evapotranspiration in eddy-covariance records from three co-located ecosystems in the Southeastern US: Implications for annual fluxes, Agr. Forest Meteorol., 149, 1491-1504, 2009.

Oishi, A. C., Oren, R., and Stoy, P. C.: Estimating components of forest evapotranspiration: A footprint approach for scaling sap flux measurements, Agr. Forest Meteorol., 148, 1719-1732, 2008.

Oliveira, P. E. S., Acevedo, O. C., Moraes, O. L. L., Zimermann, H. R., and Teichrieb, C.: Nocturnal intermittent coupling between the interior of a pine forest and the air above it, Bound.Lay. Meteorol., 146, 45-64, 2013.

Oncley, S. P., Foken, T., Vogt, R., Kohsiek, W., DeBruin, H. A. R., Bernhofer, C., Christen, A., van Gorsel, E., Grantz, D., Feigenwinter, C., Lehner, I., Liebethal, C., Liu, H., Mauder, M., Pitacco, A., Ribeiro, L., and Weidinger, T.: The Energy Balance Experiment EBEX-2000. Part I: Overview and energy balance, Bound.Lay. Meteorol., 123, 1-28, 2007.

Parrish, D. D., Hahn, C. H., Fahey, D. W., Williams, E. J., Bollinger, M. J., Hubler, G., Buhr, M. P., Murphy, P. C., Trainer, M., Hsie, E. Y., Liu, S. C., and Fehsenfeld, F. C.: Systematic variations in the concentration of $\mathrm{NO}_{x}\left(\mathrm{NO}\right.$ plus $\left.\mathrm{NO}_{2}\right)$ at Niwot Ridge, Colorado, J. Geophys. Res., 95, 1817-1836, 1990.

Parton, W., Morgan, J., Smith, D., Del Grosso, S., Prihodko, L., Lecain, D., Kelly, R., and Lutz, S.: Impact of precipitation dynamics on net ecosystem productivity, Glob. Change Biol., 18, 915-927, 2012.

Pattantyús-Ábrahám, M. and Jánosi, I. M.: What determines the nocturnal cooling timescale at $2 \mathrm{~m}$, Geophys. Res. Lett., 31 , L05109, doi:10.1029/2003GL019137, 2004.

Penman, H. L.: Natural evaporation from open water, bare soil and grass, P. Roy. Soc. Lond. A MAT, 193, 120-145, doi:10.1098/rspa.1948.0037, 1948.

Pieruschka, R., Huber, G., and Berry, J. A.: Control of transpiration by radiation, P. Nat. Acad. Sci. USA, 107, 13372-13377, 2010.

Pietersen, H. P., Vilà-Guerau de Arellano, J., Augustin, P., van de Boer, A., de Coster, O., Delbarre, H., Durand, P., Fourmentin, M., Gioli, B., Hartogensis, O., Lohou, F., Lothon, M., Ouwersloot, H. G., Pino, D., and Reuder, J.: Study of a prototypical convective boundary layer observed during BLLAST: contributions by large-scale forcings, Atmos. Chem. Phys., 15, 42414257, doi:10.5194/acp-15-4241-2015, 2015.

Pino, D., Vilà-Guerau de Arellano, J., Peters, W., Schröter, J., van Heerwaarden, C. C., and Krol, M. C.: A conceptual framework to quantify the influence of convective boundary layer development on carbon dioxide mixing ratios, Atmos. Chem. Phys., 12, 29692985, doi:10.5194/acp-12-2969-2012, 2012.

Polley, H. W., Emmerich, W., Bradford, J. A., Sims, P. L., Johnson, D. A., Sallendra, N. Z., Svejcar, T., Angell, R., Frank, A. B., Phillips, R. L., Snyder, K. A., Morgan, J. A., Sanabria, J., Mielnick, P. C., and Dugas, W. A.: Precipitation regulates the response of net ecosystem $\mathrm{CO}_{2}$ exchange to environmental variation on United States rangelands, Rangeland Ecol. Manag., 63, 176-186, 2010.

Rana, G. and Katerji, N.: Measurement and estimation of actual evapotranspiration in the field under Mediterranean climate: A review, Euro. J. Agron., 13, 125-153, 2000. 
Rasmussen, R., Baker, B., Kochendorfer, J., Meyers, T., Landolt, S., Fischer, A. P., Black, J., Theriault, J. M., Kucera, P., Gochis, D., Smith, C., Nitu, R., Hall, M., Ikeda, K., and Gutmann, E.: How well are we measuring snow? The NOAA/FAA/NCAR Winter Precipitation Test Bed, B. Am. Meteorol. Soc., 93, 811-829, 2012.

Reichstein, M., Falge, E., Baldocchi, D., Papale, D., Aubinet, M., Berbigier, P., Bernhofer, C., Buchmann, N., Gilmanov, T., Granier, A., Grunwald, T., Havrankova, K., Ilvesniemi, H., Janous, D., Knohl, A., Laurila, T., Lohila, A., Loustau, D., Matteucci, G., Meyers, T., Miglietta, F., Ourcival, J. M., Pumpanen, J., Rambal, S., Rotenberg, E., Sanz, M., Tenhunen, J., Seufert, G., Vaccari, F., Vesala, T., Yakir, D., and Valentini, R.: On the separation of net ecosystem exchange into assimilation and ecosystem respiration: Review and improved algorithm, Glob. Change Biol., 11, 1424-1439, 2005.

Riveros-Iregui, D. A., Hu, J., Burns, S. P., Bowling, D. R., and Monson, R. K.: An interannual assessment of the relationship between the stable carbon isotopic composition of ecosystem respiration and climate in a high-elevation subalpine forest, J. Geophys. Res., 116, G02005, doi:10.1029/2010JG001556, 2011.

Ryan, M. G. and Law, B.: Interpreting, measuring, and modeling soil respiration, Biogeochemistry, 73, 3-27, 2005.

Sánchez-Cañete, E. P., Kowalski, A. S., Serrano-Ortiz, P., Pérez-Priego, O., and Domingo, F.: Deep $\mathrm{CO}_{2}$ soil inhalation/exhalation induced by synoptic pressure changes and atmospheric tides in a carbonated semiarid steppe, Biogeosciences, 10, 6591-6600, doi:10.5194/bg-10-6591-2013, 2013.

Savage, K., Davidson, E. A., Richardson, A. D., and Hollinger, D. Y.: Three scales of temporal resolution from automated soil respiration measurements, Agr. Forest Meteorol., 149, 20122021, 2009.

Scanlon, T. M. and Kustas, W. P.: Partitioning carbon dioxide and water vapor fluxes using correlation analysis, Agr. Forest Meteorol., 150, 89-99, 2010.

Schaeffer, S. M., Anderson, D. E., Burns, S. P., Monson, R. K., Sun, J., and Bowling, D. R.: Canopy structure and atmospheric flows in relation to the $\delta^{13} \mathrm{C}$ of respired $\mathrm{CO}_{2}$ in a subalpine coniferous forest, Agr. Forest Meteorol., 148, 592-605, doi:10.1016/j.agrformet.2007.11.003, 2008a.

Schaeffer, S. M., Miller, J. B., Vaughn, B. H., White, J. W. C., and Bowling, D. R.: Long-term field performance of a tunable diode laser absorption spectrometer for analysis of carbon isotopes of $\mathrm{CO}_{2}$ in forest air, Atmos. Chem. Phys., 8, 5263-5277, doi:10.5194/acp-8-5263-2008, 2008b.

Schlesinger, W. H. and Jasechko, S.: Transpiration in the global water cycle, Agr. Forest Meteorol., 189, 115-117, 2014.

Schmidt, A., Hanson, C., Chan, W. S., and Law, B. E.: Empirical assessment of uncertainties of meteorological parameters and turbulent fluxes in the AmeriFlux network, J. Geophys. Res., 117, G04014, doi:10.1029/2012JG002100, 2012.

Schultz, D. M.: A review of cold fronts with prefrontal troughs and wind shifts, Mon. Weather Rev., 133, 2449-2472, 2005.

Scott-Denton, L. E., Sparks, K. L., and Monson, R. K.: Spatial and temporal controls of soil respiration rate in a high-elevation, subalpine forest, Soil Biol. Biochem., 35, 525-534, 2003.

Scott-Denton, L. E., Rosenstiel, T. N., and Monson, R. K.: Differential controls by climate and substrate over the heterotrophic and rhizospheric components of soil respiration, Glob. Change Biol., 12, 205-216, 2006.

Shuttleworth, W. J.: Experimental evidence for the failure of the Penman-Monteith equation in partially wet conditions, Bound.Lay. Meteorol., 10, 91-94, 1976.

Shuttleworth, W. J.: Putting the "vap" into evaporation, Hydrol. Earth Syst. Sc., 11, 210-244, 2007.

Staebler, R. M. and Fitzjarrald, D. R.: Observing subcanopy $\mathrm{CO}_{2}$ advection, Agr. Forest Meteorol., 122, 139-156, 2004.

Staudt, K., Serafimovich, A., Siebicke, L., Pyles, R. D., and Falge, E.: Vertical structure of evapotranspiration at a forest site (a case study), Agr. Forest Meteorol., 151, 709-729, 2011.

Stephens, B. B., Miles, N. L., Richardson, S. J., Watt, A. S., and Davis, K. J.: Atmospheric $\mathrm{CO}_{2}$ monitoring with singlecell NDIR-based analyzers, Atmos. Meas. Tech., 4, 2737-2748, doi:10.5194/amt-4-2737-2011, 2011.

Stoy, P. C., Katul, G. G., Siqueira, M. B. S., Juang, J. Y., Novick, K. A., Uebelherr, J. M., and Oren, R.: An evaluation of models for partitioning eddy covariance-measured net ecosystem exchange into photosynthesis and respiration, Agr. Forest Meteorol., 141, 2-18, 2006.

Sun, J., Burns, S. P., Delany, A. C., Oncley, S. P., Turnipseed, A. A., Stephens, B. B., Lenschow, D. H., LeMone, M. A., Monson, R. K., and Anderson, D. E.: $\mathrm{CO}_{2}$ transport over complex terrain, Agr. Forest Meteorol., 145, 1-21, doi:10.1016/j.agrformet.2007.02.007, 2007.

Tan, C. S. and Black, T. A.: Factors affecting the canopy resistance of a Douglas-fir forest, Bound.-Lay. Meteorol., 10, 475488, 1976.

Tang, J. W., Misson, L., Gershenson, A., Cheng, W. X., and Goldstein, A. H.: Continuous measurements of soil respiration with and without roots in a ponderosa pine plantation in the Sierra Nevada Mountains, Agr. Forest Meteorol., 132, 212-227, 2005.

Thomas, C. K., Law, B. E., Irvine, J., Martin, J. G., Pettijohn, J. C., and Davis, K. J.: Seasonal hydrology explains interannual and seasonal variation in carbon and water exchange in a semiarid mature ponderosa pine forest in central Oregon, J. Geophys. Res., 114, G04006, doi:10.1029/2009JG001010, 2009.

Thomas, C. K., Martin, J. G., Law, B. E., and Davis, K.: Toward biologically meaningful net carbon exchange estimates for tall, dense canopies: Multi-level eddy covariance observations and canopy coupling regimes in a mature Douglasfir forest in Oregon, Agr. Forest Meteorol., 173, 14-27, doi:10.1016/j.agrformet.2013.01.001, 2013.

Turnipseed, A. A., Blanken, P. D., Anderson, D. E., and Monson, R. K.: Energy budget above a high-elevation subalpine forest in complex topography, Agr. Forest Meteorol., 110, 177-201, 2002.

Turnipseed, A. A., Anderson, D. E., Blanken, P. D., Baugh, W. M., and Monson, R. K.: Airflows and turbulent flux measurements in mountainous terrain. Part 1: Canopy and local effects, Agr. Forest Meteorol., 119, 1-21, 2003.

Turnipseed, A. A., Anderson, D. E., Burns, S., Blanken, P. D., and Monson, R. K.: Airflows and turbulent flux measurements in mountainous terrain. Part 2: Mesoscale effects, Agr. Forest Meteorol., 125, 187-205, 2004.

Turnipseed, A. A., Burns, S. P., Moore, D. J. P., Hu, J., Guenther, A. B., and Monson, R. K.: Controls over ozone deposition to a high elevation subalpine forest, Agr. Forest Meteorol., 149, 1447-1459, doi:10.1016/j.agrformet.2009.04.001, 2009. 
Unger, S., Maguas, C., Pereira, J. S., David, T. S., and Werner, C.: The influence of precipitation pulses on soil respiration - Assessing the "Birch effect" by stable carbon isotopes, Soil Biol. Biochem., 42, 1800-1810, 2010.

van Heerwaarden, C. C., Vilà-Guerau de Arellano, J., Moene, A. F., and Holtslag, A. A. M.: Interactions between dryair entrainment, surface evaporation and convective boundarylayer development, Q. J. Roy. Meteor. Soc., 135, 1277-1291, doi:10.1002/qj.431, 2009.

van Heerwaarden, C. C., Vilà-Guerau de Arellano, J., Gounou, A., Couvreux, F., and Guichard, F.: Understanding the daily cycle of evapotranspiration: a new method to quantify the influence of forcings and feedbacks, J. Hydrometeorol., 11, 1405-1422, doi:10.1175/2010JHM1272.1, 2010.

Wang, K. C. and Dickinson, R. E.: A review of global terrestrial evapotranspiration: observation, modeling, climatology, and climatic variability, Rev. Geophys., 50, RG2005, doi:10.1029/2011RG000373, 2012.

Wang, K. C., Dickinson, R. E., and Liang, S. L.: Observational evidence on the effects of clouds and aerosols on net ecosystem exchange and evapotranspiration, Geophys. Res. Lett., 35, L10401, doi:10.1029/2008GL034167, 2008.

Werner, C., Schnyder, H., Cuntz, M., Keitel, C., Zeeman, M. J., Dawson, T. E., Badeck, F.-W., Brugnoli, E., Ghashghaie, J., Grams, T. E. E., Kayler, Z. E., Lakatos, M., Lee, X., Máguas, C., Ogée, J., Rascher, K. G., Siegwolf, R. T. W., Unger, S., Welker, J., Wingate, L., and Gessler, A.: Progress and challenges in using stable isotopes to trace plant carbon and water relations across scales, Biogeosciences, 9, 3083-3111, doi:10.5194/bg-9-30832012, 2012.

Whiteman, C. D.: Mountain Meteorology: Fundamentals and Applications, Oxford University Press, New York, 355 pp., 2000.

Williams, D. G., Cable, W., Hultine, K., Hoedjes, J. C. B., Yepez, E. A., Simonneaux, V., Er-Raki, S., Boulet, G., de Bruin, H. A. R., Chehbouni, A., Hartogensis, O. K., and Timouk, F.: Evapotranspiration components determined by stable isotope, sap flow and eddy covariance techniques, Agr. Forest Meteorol., 125, 241-258, 2004.
Williams, M. W., Losleben, M., Caine, N., and Greenland, D.: Changes in climate and hydrochemical responses in a highelevation catchment in the Rocky Mountains, USA, Limnol. Oceanogr., 41, 939-946, 1996.

Wilson, K. B., Hanson, P. J., Mulholland, P. J., Baldocchi, D. D., and Wullschleger, S. D.: A comparison of methods for determining forest evapotranspiration and its components: sap-flow, soil water budget, eddy covariance and catchment water balance, Agr. Forest Meteorol., 106, 153-168, 2001.

Woods Hole Oceanographic Institution: SEA-MAT: Matlab Tools for Oceanographic Analysis, http://woodshole.er.usgs.gov/ operations/sea-mat/, last access: 26 December 2013.

Xu, L. K., Baldocchi, D. D., and Tang, J. W.: How soil moisture, rain pulses, and growth alter the response of ecosystem respiration to temperature, Global Biogeochem. Cy., 18, GB4002, doi:10.1029/2004GB002281, 2004.

Yakir, D. and Sternberg, L. d. L.: The use of stable isotopes to study ecosystem gas exchange, Oecologia, 123, 297-311, 2000.

Yi, C., Anderson, D. E., Turnipseed, A. A., Burns, S. P., Sparks, J. P., Stannard, D. I., and Monson, R. K.: The contribution of advective fluxes to net ecosystem exchange in a high-elevation, subalpine forest, Ecol. Appl., 18, 1379-1390, doi:10.1890/060908.1, 2008.

Zardi, D. and Whiteman, C. D.: Diurnal mountain wind systems, in: Mountain Weather Research and Forecasting, edited by Chow, F. K., De Wekker, S. F. J., and Snyder, B. J., Springer Atmospheric Sciences, Springer, Dordrecht, the Netherlands, pp. 35119, Springer Netherlands, doi:10.1007/978-94-007-4098-3_2, 2013.

Zawadzki, I. I.: Statistical properties of precipitation patterns, J. Appl. Meteorol., 12, 459-472, 1973.

Zobitz, J. M., Burns, S. P., Reichstein, M., and Bowling, D. R.: Partitioning net ecosystem carbon exchange and the carbon isotopic disequilibrium in a subalpine forest, Glob. Change Biol. 14, 1785-1800, doi:10.1111/j.1365-2486.2008.01609.x, 2008. 